\title{
Lead-free perovskites: growth, properties, and applications
}

\author{
Fan Yang ${ }^{1,2}$, Aocheng Wang ${ }^{1,2}$, Shuai Yue, ${ }^{2,3}$, Wenna $\mathrm{Du}^{2,3}$, Shaoli Wang ${ }^{2,4^{*}}$, Xiaotao Zhang ${ }^{1^{*}}$ and \\ Xinfeng Liu ${ }^{2,3 *}$
}

\begin{abstract}
Lead halide perovskites have attracted extensive attention in recent years because of their excellent photoelectronic properties, such as high absorption coefficients, carrier mobilities, defect tolerances, and photoluminescence efficiencies. However, a key issue hindering their commercial application is the toxicity of lead. Replacing lead with other nontoxic elements is a promising solution to this problem. Considering their atomic radii, relative atomic masses, and electron arrangements, perovskites based on $\mathrm{Sn}, \mathrm{Bi}, \mathrm{Sb}$, and other elements instead of $\mathbf{P b}$ have been widely synthesized. Here, we summarized the growth methods, photoelectric properties, and device applications of these lead-free perovskites. First, we introduced several common growth methods for lead-free perovskites, including solution methods, solid-state reaction, and chemical vapor deposition methods. Second, we discussed the photoelectric properties and methods for optimizing these properties of lead-free perovskites with different structure dimensions. Finally, the applications of lead-free perovskites in solar cells, light-emitting diodes, and $\mathrm{X}$-ray detectors were examined. This review also provides suggestions for future research on lead-free perovskites.
\end{abstract}

Keywords: lead-free perovskites, growth methods, bandgap, photoluminescence, solar cells

\section{INTRODUCTION}

Lead halide perovskites possess a general crystal structure of $\mathrm{APbX}_{3}$, where $\mathrm{A}=\mathrm{CH}_{3} \mathrm{NH}_{3}^{+}(\mathrm{MA}), \mathrm{CH}\left(\mathrm{NH}_{2}\right)_{2}{ }^{+}(\mathrm{FA})$, or $\mathrm{Cs}^{+}$, and $\mathrm{X}=\mathrm{Cl}, \mathrm{Br}$, or I. These materials have been extensively researched since the mid-20th century [1-3]. They are widely used in solar cells, light-emitting diodes (LEDs), and piezoelectric or thermoelectric components owing to their strong light absorption capacities, low exciton binding energies and long carrier diffusion lengths [4-8]. In only nine years, the power conversion efficiency (PCE) of photovoltaic devices employing lead halide perovskites has rapidly increased from $3.8 \%$ to 25.2\% [9-16]. Lead halide perovskite nanomaterials exhibit several advantageous properties, such as high photoluminescence quantum yields (PLQYs), good optical stabilities, narrow emission widths (full width at half maximum, FWHM), and high color purities.

However, lead is a heavy metal that is harmful to the human body, and its toxicity hinders further application. Studies have shown that lead halide perovskite materials produce hydrohalic acids during the oxidation process, further increasing their toxicity to organisms [17]. To avoid toxicity concerns, researchers have attempted to replace lead with various other nontoxic elements.

To date, many significant advances have been achieved in using nontoxic elements to replace lead for lead-free perovskites [18-23]. In this paper, the growth methods, photoelectric properties, and applications of Sn-, Bi-, and $\mathrm{Sb}$-based perovskites are discussed. First, several common methods to synthesize lead-free perovskites are summarized. Then, the photoelectric properties of lead-free perovskites based on different structure dimensions are discussed. Finally, applications of these materials in solar cells, LEDs, and X-ray detectors are considered. This review provides suggestions for the future development of

\footnotetext{
${ }^{1}$ Tianjin Key Laboratory of Molecular Optoelectronic Science, Department of Chemistry, School of Science, Tianjin 300072, China

${ }^{2}$ CAS Key Laboratory of Standardization and Measurement for Nanotechnology, CAS Center for Excellence in Nanoscience, National Center for Nanoscience and Technology, Beijing 100190, China

${ }^{3}$ University of Chinese Academy of Sciences, Beijing 100049, China

${ }^{4}$ Experiment Center of Forestry in North China, Chinese Academy of Forestry, Beijing 102300, China

* Corresponding authors (emails: liuxf@nanoctr.cn (Liu X); zhangxt@tju.edu.cn (Zhang X); wshaoli@iccas.ac.cn (Wang S))
} 
novel lead-free perovskites.

\section{GROWTH METHODS OF LEAD-FREE PEROVSKITES}

\section{Solution methods}

Solution-based methods are the most commonly used techniques to synthesize perovskites of various morphologies; they are also easily controlled and inexpensive [24]. In this section, four different methods are introduced: reduced solution saturation, spin-coating, hot injection, and the hydrothermal methods.

\section{Reduced solution saturation method}

Many techniques have been applied to reduce the solution saturation point, such as changing the temperature or using an anti-solvent to precipitate crystals. Ju et al. [25] reduced the solubility of $\mathrm{MA}_{3} \mathrm{Sb}_{2} \mathrm{I}_{9}$ in a $\mathrm{HI}$ acid solution by slowly lowering the temperature. They dissolved $\mathrm{CH}_{5} \mathrm{~N}, \mathrm{HCl}, \mathrm{SbCl}_{3}$, and $\mathrm{SnO}$ in $\mathrm{HI}$, and heated the mixture at $220^{\circ} \mathrm{C}$ for $24 \mathrm{~h}$, followed by slow cooling at a rate of $5^{\circ} \mathrm{C} \mathrm{h}^{-1}$ to obtain a $\mathrm{Sn}$-doped $\mathrm{MA}_{3} \mathrm{Bi}_{2} \mathrm{I}_{9}$ single crystal
(SC). Zhang et al. [26] placed the $\mathrm{Cs}_{3} \mathrm{Bi}_{2} \mathrm{I}_{9}$ precursor solution on a hot plate covered with aluminum foil containing holes to accelerate the solvent volatilization, as shown in Fig. 1a, and slowly lowered the temperature from $60^{\circ} \mathrm{C}$ to $50^{\circ} \mathrm{C}$ over 3 days to obtain a millimeterscale $\mathrm{Cs}_{3} \mathrm{Bi}_{2} \mathrm{I}_{9}$ SC (Fig. 1b). Owing to the different solubilities of perovskite compounds in various solvents, an anti-solvent crystal growth method was proposed $[27,28]$. For example, Zuo and Ding [29] reported that $\mathrm{NH}_{4} \mathrm{I}$ and $\mathrm{SbI}_{3}$ were more soluble in ethanol than in $\mathrm{CHCl}_{3}$ (antisolvent); therefore, they placed an ethanol solution of $\left(\mathrm{NH}_{4}\right)_{3} \mathrm{Sb}_{2} \mathrm{I}_{9}$ in a beaker of $\mathrm{CHCl}_{3}$ and sealed it. The evaporation of $\mathrm{CHCl}_{3}$ accelerated the precipitation of $\left(\mathrm{NH}_{4}\right)_{3} \mathrm{Sb}_{2} \mathrm{I}_{9}$ crystals.

\section{Spin-coating method}

The spin-coating process allows the dispersion of a precursor solution on a substrate. As the solvent evaporates, the precursor solution reaches supersaturation and perovskite grains begin to nucleate. In this process, the solvent evaporation rate affects the grain nucleation process. An annealing process is normally adopted to evaporate
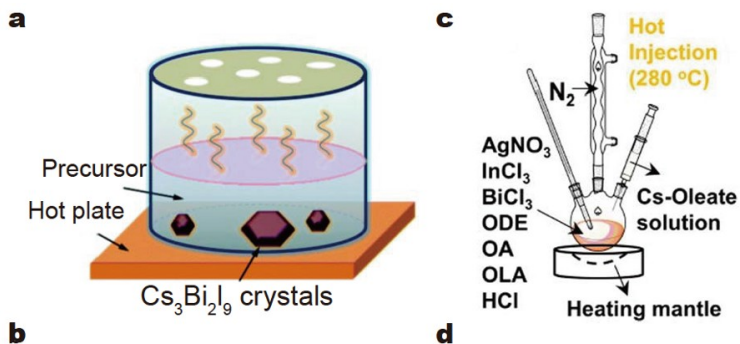

d
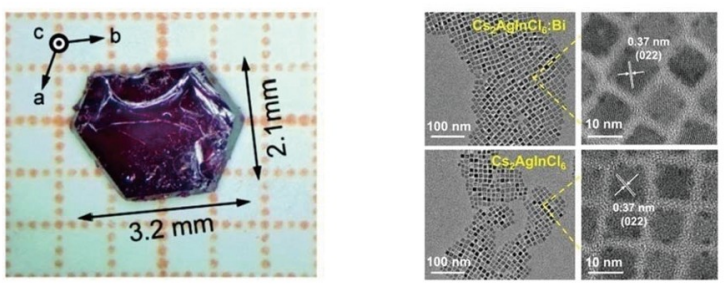

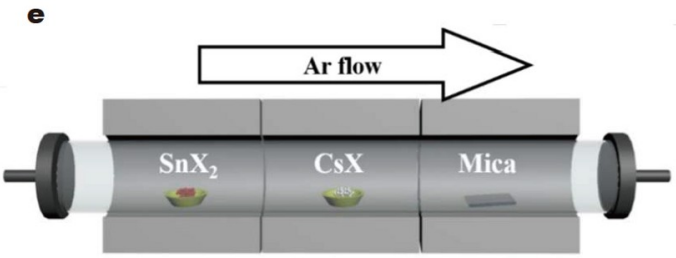

f

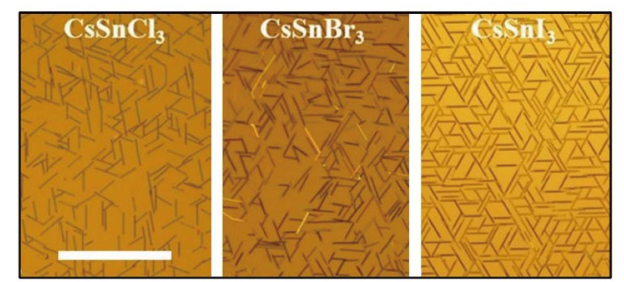

g
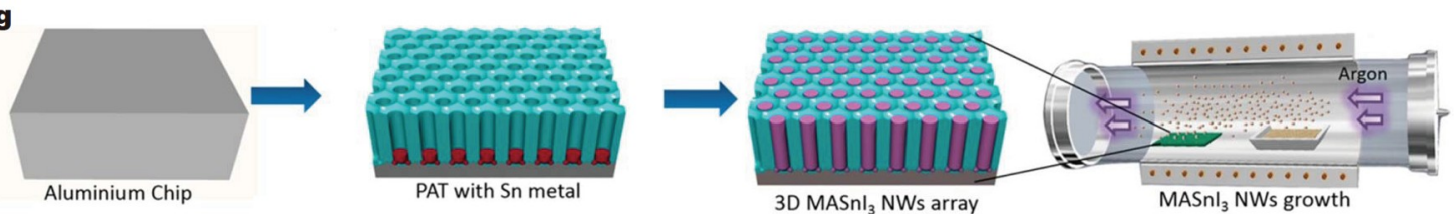

Figure 1 (a) Schematic of the reduced solution saturation method used to synthesize $\mathrm{Cs}_{3} \mathrm{Bi}_{2} \mathrm{I}_{9} \mathrm{SCs}$. (b) Digital photograph of $\mathrm{Cs}_{3} \mathrm{Bi}_{2} \mathrm{I}_{9} \mathrm{SCs}$. (a) and (b) are reprinted with permission from Ref. [26]. Copyright 2018, the Royal Society of Chemistry. (c) Synthesis of $\mathrm{Cs}_{2} \mathrm{AgBiCl}_{6}$ QDs by the hot injection method. (d) Transmission electron microscopy (TEM) and high-resolution TEM (HRTEM) images of Bi-doped $\mathrm{Cs}_{2} \mathrm{AgInCl}_{6} \mathrm{NCs}$ and undoped $\mathrm{Cs}_{2} \mathrm{AgInCl}_{6}$ NCs. (c) and (d) are reprinted with permission from Ref. [39]. Copyright 2019, the American Chemical Society. (e) Schematic of CsSnX 3 nanowires prepared by CVD. (f) Optical images of $\mathrm{CsSnI}_{3}, \mathrm{CsSnBr}_{3}$, and $\mathrm{CsSnCl}_{3}$ nanowires. The scale bar is $100 \mu \mathrm{m}$. (e) and (f) are reprinted with permission from Ref. [44]. Copyright 2019, the American Chemical Society. (g) Process for the CVD growth of vertically aligned MASnI 3 nanowires on a porous alumina template. Reprinted with permission from Ref. [45]. Copyright 2017, the American Chemical Society. 
the solvent more quickly. A uniform and dense film is necessary to achieve excellent device performance. However, it is difficult to obtain a high-quality film using simple spin-coating [30-32].

Hong et al. [33] prepared $\mathrm{CsSnI}_{3}$ thin films using a onestep spin-coating method. They added equal amounts of CsI and $\mathrm{SnI}_{2}$ to dimethyl sulfoxide (DMSO) to prepare a precursor solution. This precursor solution $(50 \mu \mathrm{L})$ was spin-coated on indium tin oxide (ITO) glass at a speed of $4000 \mathrm{rpm}$. After $30 \mathrm{~s}$, toluene was dropped onto the center of the substrate, followed by annealing at $90^{\circ} \mathrm{C}$ for $10 \mathrm{~min}$ to yield a dense black film. In this process, toluene acted as an anti-solvent and was essential in improving the film quality. Xi et al. [34] prepared $\mathrm{FASnI}_{3}$ thin films using a multi-step spin-coating and evaporation process. They used water to dissolve formamidinium iodide (FAI) and then added poly(3,4-ethylenedioxythiophene):polystyrene sulfonate (PEDOT:PSS). This FAI/PEDOT:PSS aqueous solution was spin-coated on an ITO substrate coated with PEDOT:PSS, which was then annealed. The addition of PEDOT:PSS produced a less dendritic film structure in which minute spherical FAI crystals were formed. Subsequently, the film was moved to a vacuum chamber for evaporation of $\mathrm{SnI}_{2}$ and annealed. The $\mathrm{FASnI}_{3}$ thin film formed was compact with no pinholes observed owing to the large contact area of the small FAI crystal spheres with $\mathrm{SnI}_{2}$.

\section{Hot injection method}

Hot injection is a universal method to prepare perovskite nanocrystals (NCs) [35-37]. A precursor solution is prepared at high temperatures in nitrogen environment. The precursor solution is then injected into a high-temperature reaction solution at a suitable temperature to rapidly nucleate and grow NCs. After cooling in an ice water bath, the NCs can be recovered by centrifugation. The temperature during injection and the reaction time after injection are key factors governing the morphology of the final products. Jellicoe et al. [38] first reported adjustable-bandgap $\mathrm{CsSnX}_{3}$ NCs synthesized using the hot injection method in 2016. They dissolved $\mathrm{SnX}_{2}$ powder in trioctyl phosphine, a mildly reductive coordination solvent, to obtain a precursor solution. This solution was injected into a high-temperature $\mathrm{Cs}_{2} \mathrm{CO}_{3}$ solution containing oleic acid (OA) and oleylamine $(\mathrm{OAm})$ to yield stable $\mathrm{CsSnX}_{3}$ perovskite NCs. Liu et al. [39] synthesized $\mathrm{Cs}_{2} \mathrm{AgInCl}_{6}$ quantum dots (QDs) using the hot injection method (Fig. 1c and d). They added $\mathrm{BiCl}_{3}$ to a precursor solution of $\mathrm{Cs}_{2} \mathrm{AgInCl}_{6}$ to realize $\mathrm{Bi}$ doping, thus obtaining $\mathrm{Cs}_{2} \mathrm{AgInCl}_{6}: \mathrm{Bi}$ QDs exhibiting broadband orange emission and a high PLQY.

\section{Hydrothermal method}

Like the other solution methods, the hydrothermal method is a common technique to prepare perovskite crystals. Typically, it involves placing a precursor solution in a reaction kettle, reacting at a high temperature and pressure, and separating and washing steps to obtain the crystals. Zhou et al. [40] synthesized $\mathrm{Cs}_{2} \mathrm{AgInCl}_{6} \mathrm{SCs}$ using the hydrothermal method. They added $\mathrm{HCl}$ to a mixture of $\mathrm{CsCl}, \mathrm{AgCl}$, and $\mathrm{InCl}_{3}$ in a high-pressure reactor. This was heated to $150^{\circ} \mathrm{C}$ and then cooled to room temperature to induce particle nucleation and growth. White $\mathrm{Cs}_{2} \mathrm{AgInCl}_{6}$ crystals were obtained after filtration and washing with ethanol. Zhou et al. [41] reported the successful synthesis of low-dimensional perovskite crystals using the hydrothermal method. Equal amounts of $\mathrm{SnBr}_{2}$ and $\mathrm{C}_{4} \mathrm{H}_{14} \mathrm{~N}_{2} \mathrm{Br}_{2}$ powders in a liquid mixture of $\mathrm{HBr}$ and $\mathrm{H}_{3} \mathrm{PO}_{2}$ were heated and stirred. After dissolution and cooling to room temperature, $\mathrm{C}_{4} \mathrm{~N}_{2} \mathrm{H}_{14} \mathrm{SnBr}_{4}$ nanowires were obtained.

\section{Solid-state reaction}

In general, solid-state reactions include two processes: a reaction at an interface and material migration. This technique is usually employed to mix the reactant particles evenly. At high temperatures, chemical reactions occur on the surface of the reactant to produce a new phase containing structural defects. This is followed by structural adjustment and crystal growth of the new phase. Chung et al. [42] obtained $\mathrm{CsSnI}_{3}$ in a pure orthogonal phase using a solid-state reaction. They mixed CsI and $\mathrm{SnI}_{2}$ powders in an evacuated Pyrex tube, performed the reaction at $550^{\circ} \mathrm{C}$ for $1 \mathrm{~h}$, and cooled the tube to room temperature over $6 \mathrm{~h}$ to grow SCs. Benin et al. [43] placed a solid mixture of $\mathrm{CsBr}$ and $\mathrm{SnBr}_{2}$ particles (molar ratio 4.5:1) in a sealed Pyrex tube and heated it to $350^{\circ} \mathrm{C}$ for $60 \mathrm{~h}$, after which the tube was opened, and the above process was repeated in a glove box. This procedure produced the pure $\mathrm{Cs}_{4} \mathrm{SnBr}_{6}$ phase.

\section{Chemical vapor deposition (CVD) method}

CVD is used to grow perovskites with various morphologies and few defects. In a simple CVD system, the reactants and substrate are placed in a chamber at a set distance from each other. An inert air flow carries the reactants from the high-temperature region to the lowtemperature substrate surface, where deposition occurs. The excess reactants and unreacted precursor gases are discharged from the chamber along with chemical by- 
products. Han et al. [44] synthesized $\mathrm{CsSnX}_{3}$ nanowires (Fig. 1f) by CVD. As shown in Fig. 1e, they divided the CVD tube into three regions and placed $\mathrm{SnX}_{2}$ powder upstream in the airflow, CsX powder midstream, and a mica substrate downstream. The $\mathrm{SnX}_{3}, \mathrm{CsX}_{3}$, and mica substrate were heated to 220-350, 610-670, and $200-260^{\circ} \mathrm{C}$, respectively, in an argon atmosphere, and the pressure in the tube was maintained at 0.16 Torr for 20 min. Waleed et al. [45] utilized a porous alumina template as a substrate to grow vertically aligned $\mathrm{MASnI}_{3}$ nanowires (Fig. 1g). They deposited tin nanoclusters in the nanopores of the template and placed it in a tubular furnace. With Ar as a carrier gas, MAI was deposited in the nanopores to complete the reaction, producing $\mathrm{MASnI}_{3}$ nanowires. The nanowires were not only regularly shaped, but they also were resistant to water and oxygen owing to their small contact surfaces.

\section{PROPERTIES OF LEAD-FREE PEROVSKITES}

\section{$\mathrm{Sn}$ (II)-based $\mathrm{ABX}_{3}$ perovskites}

Tin has two predominant valence states, $\mathrm{Sn}^{2+}$ and $\mathrm{Sn}^{4+}$, allowing for the formation of three-dimensional $\mathrm{ASn}(\mathrm{II}) \mathrm{X}_{3}$ and zero-dimensional $\mathrm{A}_{2} \mathrm{Sn}(\mathrm{IV}) \mathrm{X}_{6}$ perovskite structures. As shown in the crystal structure of $\mathrm{ASn}(\mathrm{II}) \mathrm{X}_{3}$ (Fig. 2a), eight coordinated A-site cations are located at the corners, a Sn(II) cation is located at the center, and six nearest-neighbor $\mathrm{X}$ anions form eight planes, thus creating an octahedral $\mathrm{SnX}_{6}$ structure. Each octahedron can be infinitely extended by connecting the vertices to form a three-dimensional perovskite structure. In addition, the tolerance factor $(t)$ and the octahedral factor $(\mu)$ can be calculated using the following formula [38]:

$t=R_{A}+\frac{R_{B}}{\left[\sqrt{2}\left(R_{B}+R_{X}\right)\right]}$,

$\mu=\frac{R_{\mathrm{B}}}{R_{\mathrm{X}}}$,

where $R_{\mathrm{A}}, R_{\mathrm{B}}$, and $R_{\mathrm{X}}$ represent the effective radii of $\mathrm{A}, \mathrm{B}$, and $\mathrm{X}$ ions. Specifically, tolerance factor $t$ should be close to $0.9-1.0$ to obtain the cubic-phase crystal structure, and octahedral factor $\mu$ should exceed 0.41 to maintain stability [46]. Yin et al. [47] summarized a series of $t$ and $\mu$ values for common perovskites, as shown in Fig. $2 \mathrm{~b}$ and c. The $t$ value of an organic/inorganic hybrid tin(II) halide perovskite is close to 1 ; for example, the values for $\mathrm{FASnCl}_{3}, \mathrm{MASnCl}_{3}$, and $\mathrm{CsSnCl}_{3}$ are between 0.85 and 0.95 . Therefore, the stability of a perovskite can be improved by adjusting the A-site composition without changing the halogen composition. In addition, if the halogen is changed from $\mathrm{Cl}$ to I, the stability decreases. Taking $\mathrm{CsSnX}_{3}$ as an example, $\mathrm{CsSnCl}_{3}$ exhibits a highly symmetrical $P m 3 m$ cubic-phase perovskite structure with superior stability, while $\mathrm{CsSnBr}_{3}$ and $\mathrm{CsSnI}_{3}$ exhibit orthorhombic phases that belong to the lower-symmetry Pnma space group. This is consistent with the tolerance and octahedral factor calculations. To summarize, the divalent Sn-based halide perovskite crystal structure exhibits a high degree of symmetry.

Like lead halide perovskites, divalent tin perovskites also exhibit adjustable bandgaps. By changing the ratio of the halide composition, the bandgap can be continuously adjusted from 1.69 to $3.34 \mathrm{eV}$ [48]. Yuan et al. [49] reported the absorption and photoluminescence (PL) spectra of bulk $\mathrm{Sn}$ (II)-based $\mathrm{CsSnX}_{3}$ perovskite films (Fig. 2d). The emission peak of $\mathrm{CsSnCl}_{3}$ was close to $440 \mathrm{~nm}$, while that of $\mathrm{CsSnBr}_{0.5} \mathrm{I}_{2.5}$ was located in the near-infrared region at $\sim 920 \mathrm{~nm}$. When $\mathrm{Cs}^{+}$was substituted with a smaller $\mathrm{MA}^{+}$amino group, the PL peak was slightly blue-shifted. In addition, the $\mathrm{ASn}(\mathrm{II}) \mathrm{X}_{3}$ perovskite exhibits excellent photoelectric properties, making it suitable for device fabrication. In 1999, Kagan et al. [50] reported the fabrication of high-efficiency field-effect transistors with high carrier mobility, based on layered tin perovskites. Stoumpos et al. [51] measured the resistivities of $\mathrm{MASnI}_{3}$ and $\mathrm{FASnI}_{3}$ at $300 \mathrm{~K}$ to be 0.49 and $11.8 \Omega \mathrm{cm}$, respectively (Fig. $2 \mathrm{e}$ and $2 \mathrm{f}$ ). The electron mobilities of $\mathrm{MASnI}_{3}$ and $\mathrm{FASnI}_{3}$ were calculated to be 2320 and $103 \mathrm{~cm}^{2} \mathrm{~V}^{-1} \mathrm{~s}^{-1}$, respectively, according to the formula $\mu=1$ ne $\rho^{-1}$. As candidate materials for photovoltaic cells, Sn-based perovskites exhibit excellent photoelectric properties, such as high absorption coefficients, long diffusion lengths, and low defect tolerances. Wu et al. [52] reported a diffusion length of $1 \mu \mathrm{m}$, a bulk carrier lifetime close to $6.6 \mathrm{~ns}$, and a doping concentration of approximately $4.5 \times 10^{17} \mathrm{~cm}^{-3}$ for melt-synthesized $\mathrm{CsSnI}_{3}$ ingots. Sn(II)-based perovskites are direct-bandgap semiconductors with narrower bandgaps than their lead-based analogs. For example, the bandgap of $\mathrm{MASnI}_{3}$ ranges from 1.2 to $1.4 \mathrm{eV}$, suggesting that the absorption spectrum of $\mathrm{MASnI}_{3}$ can be extended to the near-infrared region [51].

\section{Double perovskites}

The molecular formula for double perovskites can be expressed as $\mathrm{A}_{2} \mathrm{~B}^{\prime}(\mathrm{I}) \mathrm{B}^{\prime \prime}(\mathrm{III}) \mathrm{X}_{6}$, corresponding to a combination of two perovskites of formula $\mathrm{AB}(\mathrm{II}) \mathrm{X}_{3}$. These materials are called glaciolite or potassium glaciolite. In double perovskite $\mathrm{Cs}_{2} \mathrm{AgInCl}_{6}$, the alternating arrange- 



Figure 2 (a) Unit cell of the $\mathrm{ASn}(\mathrm{II}) \mathrm{X}_{3}$ perovskite. $\mathrm{Cs}^{+}$and $\mathrm{MA}^{+}$represent inorganic and organic cations at the A site. (b) Tolerance factors $(t)$ of various perovskites. (c) Octahedral factors ( $\mu$ ) of various perovskites. (b) and (c) are reprinted with permission from Ref. [47]. Copyright 2019, Wiley. (d) Normalized absorption and steady-state PL spectra of pure- and mixed-halogen $\mathrm{CsSnX}_{3}$ films. Reprinted with permission from Ref. [49]. Copyright 2018, Wiley. Single-crystal resistivities of (e) $\mathrm{MASnI}_{3}$ and (f) $\mathrm{FASnI}_{3}$ in the range of 5-330 K. Reprinted with permission from Ref. [51]. Copyright 2013, the American Chemical Society.

ment of $\left[\mathrm{AgCl}_{6}\right]$ and $\left[\mathrm{InCl}_{6}\right]$ octahedra forms a double perovskite skeleton, with $\mathrm{Cs}^{+}$supported between the octahedra (Fig. 3). $\mathrm{Li}^{+}, \mathrm{Na}^{+}, \mathrm{K}^{+}, \mathrm{Rb}^{+}, \mathrm{Ag}^{+}$, etc., can be employed as the $\mathrm{B}^{\prime}(\mathrm{I})$ ion in double perovskites; $\mathrm{Al}^{3+}, \mathrm{Ga}^{3+}$, $\mathrm{In}^{3+}, \mathrm{Bi}^{3+}, \mathrm{Sb}^{3+}$ and some lanthanides can be used as the $\mathrm{B}^{\prime \prime}$ (III) element. However, not every combination forms a corresponding double perovskite. Moreover, because the photoelectric properties of perovskites are primarily determined by the $\left[\mathrm{BX}_{6}\right]$ unit, double perovskites composed of two different $B$ elements are significantly more complicated than $\mathrm{ABX}_{3}$ perovskites.

\section{$\mathrm{Cs}_{2} \mathrm{AgBiX}_{6}$}

In contrast to direct-bandgap inorganic lead halide perovskites, $\mathrm{Cs}_{2} \mathrm{AgBiX}_{6}$ generally exhibits an indirect bandgap. This is because the valence band maximum (VBM) is moved from the (111) Brillouin zone boundary (the Rpoint in a primitive cubic cell and the L-point in a facecentered cubic cell) to the X-point. The valence band of

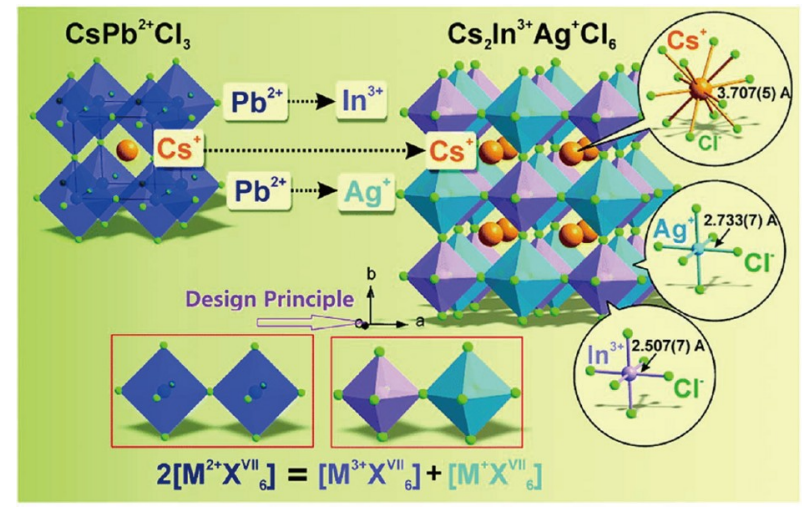

Figure 3 Crystal structures for $\mathrm{CsPbCl}_{3}$ and $\mathrm{Cs}_{2} \mathrm{AgInCl}_{6}$ showing the $\left[\mathrm{BX}_{6}\right]$ octahedra present in these $\mathrm{AB}(\mathrm{II}) \mathrm{X}_{3}$ perovskite-type compounds. The general design principle for chemical unit co-substitution is also shown. Reprinted with permission from Ref. [40]. Copyright 2019, Wiley.

$\mathrm{Cs}_{2} \mathrm{AgBiX}_{6}$ consists of $3 \mathrm{p} / 4 \mathrm{p}$ halogen orbitals and $\mathrm{Ag} 4 \mathrm{~d}$ orbitals. The valence-to-conduction-band transition oc- 
curs from the $3 \mathrm{p} / 4 \mathrm{p}$ halogen state to the anti-bonding $\mathrm{Ag} 5 \mathrm{~s}$ and Bi 6p states (Fig. $4 \mathrm{a}$ and b) [53]. $\mathrm{Cs}_{2} \mathrm{AgBiBr}_{6} \mathrm{SC}$ exhibits an indirect bandgap of $1.95 \mathrm{eV}$, a long roomtemperature PL lifetime of $660 \mathrm{~ns}$, and an inherently high defect tolerance (Fig. 4c) [54]. It also displays an obvious thermochromic phenomenon: with increasing temperature, the color of the SC changes from red to black. Experimental results and theoretical calculations showed that the $\mathrm{Ag}-\mathrm{Br}$ and $\mathrm{Bi}-\mathrm{Br}$ bond lengths increased during heating, and harmonic fluctuations were observed at high temperatures (Fig. 4d and e). These phenomena, along with the inherently strong electron-phonon and spinorbit coupling, produced thermochromism. In addition, lattice expansion did not change the phase; the color returned to red when the sample was cooled to room temperature (Fig. 4d) [55]. Li et al. [56] reported that under a pressure of $3 \mathrm{GPa}$, cubic-phase $\mathrm{Cs}_{2} \mathrm{AgBiBr}_{6}$ exhibited $\left[\mathrm{AgBr}_{6}\right]$ and $\left[\mathrm{BiBr}_{6}\right]$ octahedral compression, resulting in orbital overlap and causing bandgap reduction. When the pressure was above $3 \mathrm{GPa}$, the cubic phase was transformed into a tetragonal phase. The decreased $\mathrm{Ag}-\mathrm{Br}-\mathrm{Bi}$ bond angle reduced the $\mathrm{Bi} 6 \mathrm{p} / \mathrm{Ag} 4 \mathrm{~d}$ and $\mathrm{Br} 4 \mathrm{p}$ orbital coupling, increasing the bandgap. When the pressure was released, the bandgap was $8.2 \%$ smaller than that observed initially, demonstrating the excellent reversibility of the system (Fig. $4 \mathrm{~g}$ ).

Bekenstein et al. [57] observed sharp absorption peaks for $\mathrm{Cs}_{2} \mathrm{AgBiBr}_{6}$ at $430 \mathrm{~nm}$ and for $\mathrm{Cs}_{2} \mathrm{AgBiCl}_{6}$ at $365 \mathrm{~nm}$, $1 \mathrm{eV}$ higher than the band edge energy. They suggested that this difference was due to a localized $\mathrm{Bi} 6 s-6 \mathrm{p}$ transition rather than to a confined exciton (Fig. 5a). Yang et al. [58] synthesized $\mathrm{Cs}_{2} \mathrm{AgBiX}_{6} \mathrm{NCs}$ with a tun-

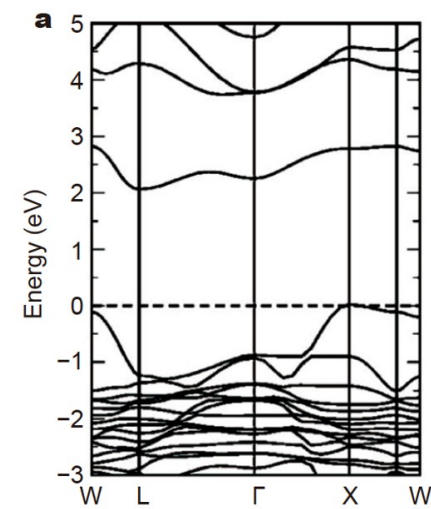

d
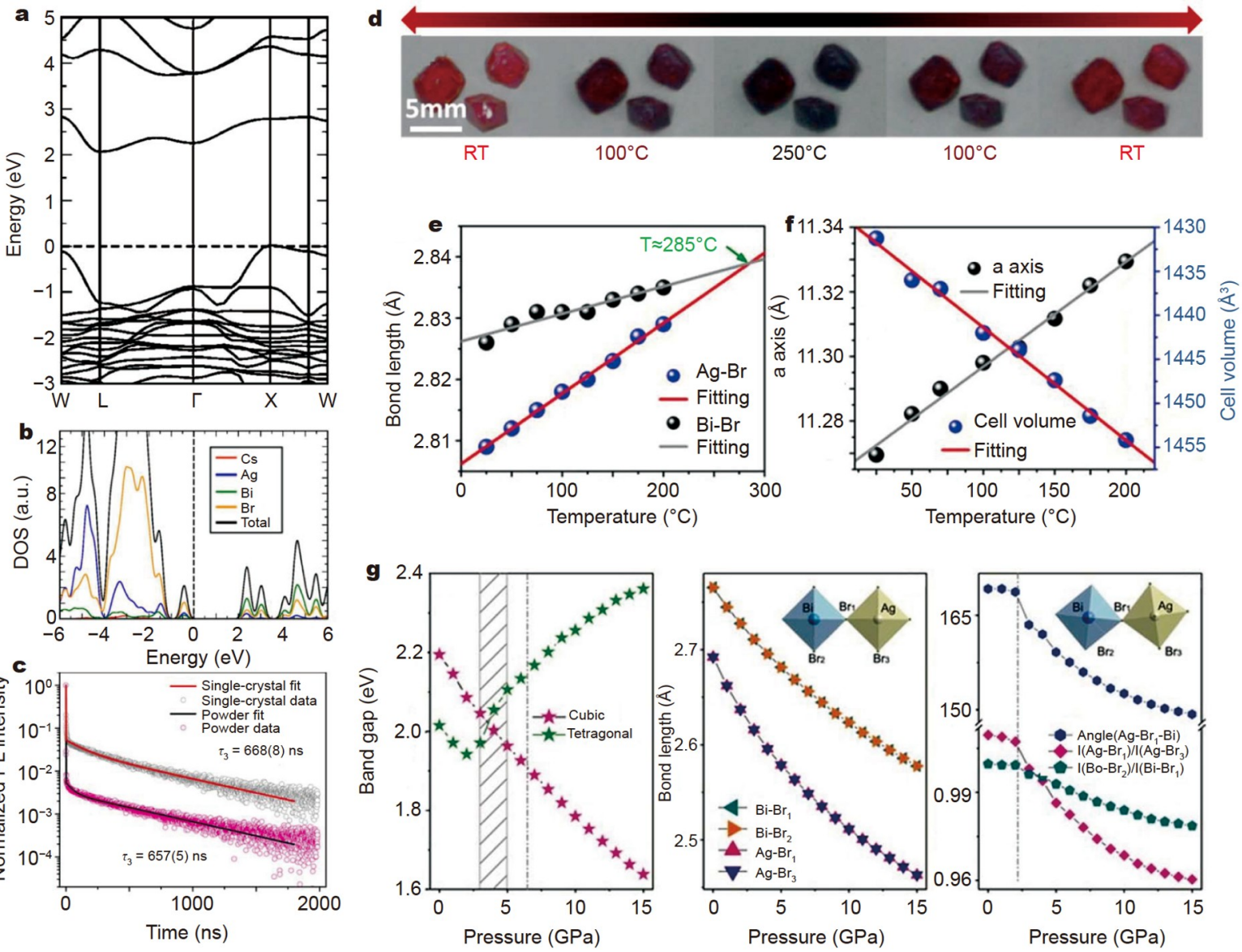

Figure 4 (a) Band structure diagram for $\mathrm{Cs}_{2} \mathrm{AgBiBr}_{6}$. (b) Atomic partial density of states plots for $\mathrm{Cs}_{2} \mathrm{AgBiBr}_{6}$. (a) and (b) are reprinted with permission from Ref. [53]. Copyright 2016, the American Chemical Society. (c) Time-resolved PL and fits of the PL decay time $(\tau)$ for both powder and single-crystal $\mathrm{Cs}_{2} \mathrm{AgBiBr}_{6}$ at room temperature. Reprinted with permission from Ref. [54]. Copyright 2016, the American Chemical Society. (d) Images of single-crystal $\mathrm{Cs}_{2} \mathrm{AgBiBr}_{6}$ during heating and cooling. (e) $\mathrm{Ag}-\mathrm{Br}$ and $\mathrm{Bi}-\mathrm{Br}$ bond lengths varying with temperature. (f) Temperaturedependent cell parameters of SCs: $a$-axis and cell volume $V$. (d-f) are reprinted with permission from Ref. [55]. Copyright 2019, Wiley. (g) Left: bandgap variation with pressure for cubic and tetragonal $\mathrm{Cs}_{2} \mathrm{AgBiBr}_{6}$. Middle: variation with pressure of the $\mathrm{Ag}-\mathrm{Br}$ and $\mathrm{Bi}-\mathrm{Br}$ bond lengths in $\mathrm{Cs}_{2} \mathrm{AgBiBr}_{6}$. Right: ratio of the bond angle to the bond length under compression. Reprinted with permission from Ref. [56]. Copyright 2017, Wiley. 
able emission range from 395 to $575 \mathrm{~nm}$. The NCs exhibited a sub-bandgap trapping state derived from surface defects, which could be passivated by OA. In addition, a hot-carrier cooling process was observed in $\mathrm{Cs}_{2} \mathrm{AgBiBr}_{6}$, competing with sub-bandgap recombination (Fig. $5 \mathrm{~b}-\mathrm{d}$ ).

The $\mathrm{Na}^{+}$-doped $\mathrm{Cs}_{2}\left(\mathrm{Na}_{x} \mathrm{Ag}_{1-x}\right) \mathrm{BiCl}_{6}$ double perovskite broke the parity transition rule in $\mathrm{Cs}_{2} \mathrm{AgBiCl}_{6}$, transforming from a dark state to a radiative transition and exhibiting over 30 -fold enhancement in PL intensity. $\mathrm{Na}$ did not contribute to the conduction or valence bands; thus, with increasing $\mathrm{Na}$ content, the contribution of $\mathrm{Ag}$ to the valence band decreased, increasing the bandgap (Fig. 6) [59]. Yb-doped $\mathrm{Cs}_{2} \mathrm{AgBiX}_{6}$ presented good lattice matching with near-infrared emission observed at approximately $1000 \mathrm{~nm}$. This originated from the $\mathrm{Yb}^{3+}{ }^{2} \mathrm{~F}_{5 / 2}$ $\rightarrow{ }^{2} \mathrm{~F}_{7 / 2} \mathrm{f}-\mathrm{f}$ transition, as well as intrinsic trap-state PL. The emission spectra and photon relaxation dynamics of double perovskite NCs can be easily adjusted by controlling the $\mathrm{Yb}$ doping concentration [60].

$\mathrm{Cs}_{2} \operatorname{InAgX} X_{6}$

In $\mathrm{Cs}_{2} \mathrm{InAgCl}_{6}$, the bottom of the conduction band is composed of $\mathrm{Cl} 3 \mathrm{p}$, In $5 \mathrm{~s}$, and $\mathrm{Ag} 5 \mathrm{~s}$ states, whereas the top of the valence band is composed of $\mathrm{Cl} 3 \mathrm{p}$, In $4 \mathrm{~d}$, and $\mathrm{Ag} 4 \mathrm{~d}$ states. No In $\mathrm{s}$ orbital is present at the top of the valence band, creating a direct bandgap. The compound exhibits a direct bandgap of $3.3 \mathrm{eV}$ and belongs to the $\mathrm{Fm} 3 m$ space group, similar to $\mathrm{Cs}_{2} \mathrm{AgBiX}_{6}$. $\mathrm{Cs}_{2} \mathrm{AgInCl}_{6}$ also displayed a sub-bandgap state. Under UV excitation, the photoinduced defect state emitted light at $2.1 \mathrm{eV}$ [61]. VBM and conduction band minimum (CBM) of $\mathrm{Cs}_{2} \mathrm{AgInCl}_{6}$ were even in parity; therefore, a forbidden transition occurred between band edge states at the $\mathrm{G}$ point (see the dashed blue arrow in Fig. 7a) [40]. This phenomenon generated dark self-trapping excitons, lowering the PLQY. Luo et al. [62] reported a strong JahnTeller distortion in the $\left[\mathrm{AgCl}_{6}\right]$ octahedra. They introduced $\mathrm{Na}$ ions that did not affect the conduction or valence band, retaining the lattice structure of $\mathrm{Cs}_{2} \mathrm{AgInCl}_{6}$.

When an appropriate amount of $\mathrm{Na}$ was introduced, the electron wave function symmetry was destroyed, and the electron and hole wave functions overlapped. This disrupted the forbidden transition, and broad white emission with a high PLQY (86\%) was observed. However, as the amount of $\mathrm{Na}$ was increased further, the
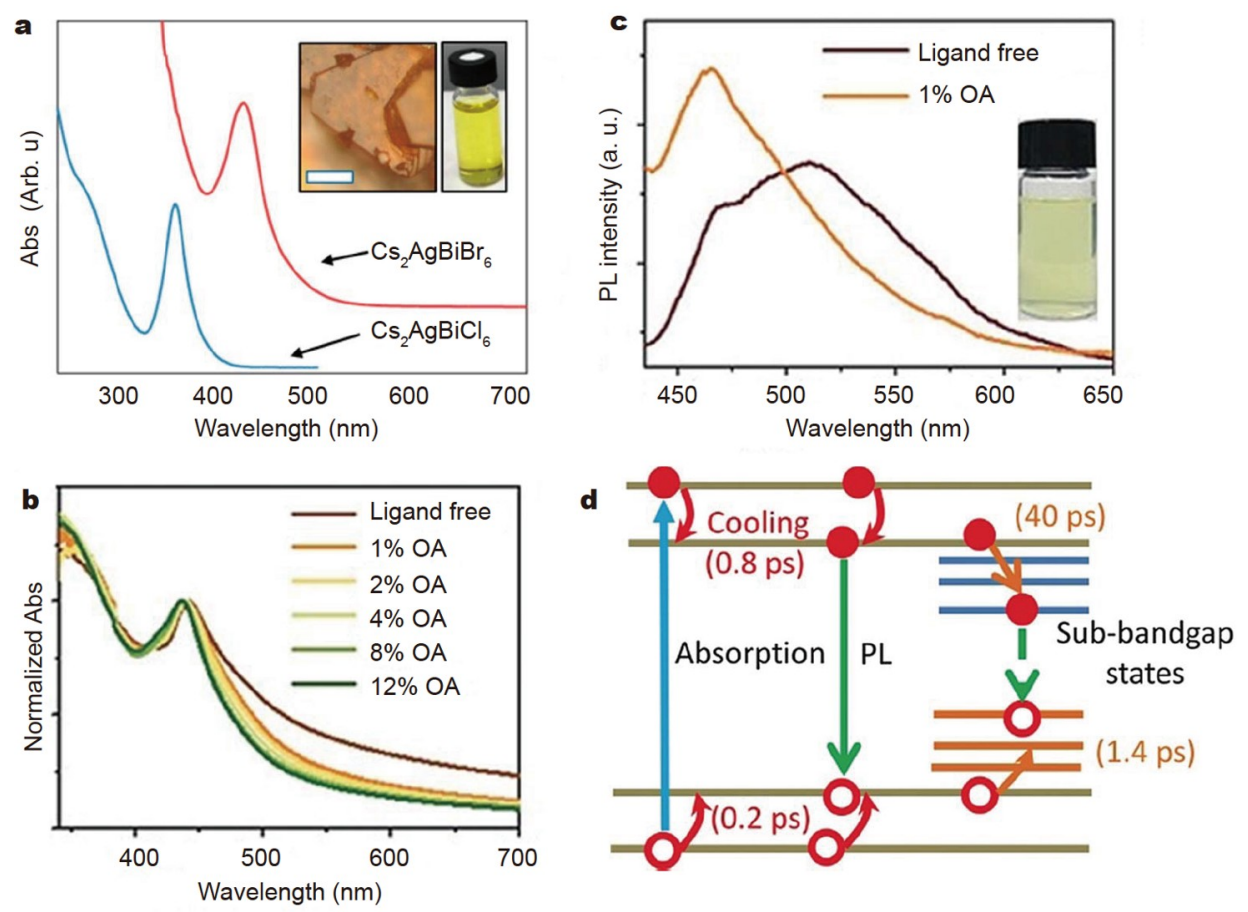

Figure 5 (a) Absorption spectra for $\mathrm{Cs}_{2} \mathrm{AgBiBr}_{6}$ and $\mathrm{Cs}_{2} \mathrm{AgBiCl}_{6} \mathrm{NCs}$. Insets: $\mathrm{Cs}_{2} \mathrm{AgBiBr}_{6} \mathrm{NCs}$ suspension and the orange/red $\mathrm{Cs}_{2} \mathrm{AgBiBr}_{6}$ bulk crystal. The scale bar is $1 \mathrm{~mm}$. Reprinted with permission from Ref. [57]. Copyright 2018, the American Chemical Society. (b) Absorption spectra for ligand-free and OA-capped $\mathrm{Cs}_{2} \mathrm{AgBiBr}_{6}$ NCs. (c) PL spectra for ligand-free and 1\% OA-capped NCs. Inset: digital photograph of the colloidal ligandfree $\mathrm{Cs}_{2} \mathrm{AgBiBr}_{6}$ NCs. (d) Schematic of the carrier dynamics in $\mathrm{Cs}_{2} \mathrm{AgBiBr}_{6}$ NCs. (b-d) are reprinted with permission from Ref. [58]. Copyright 2018, Wiley. 

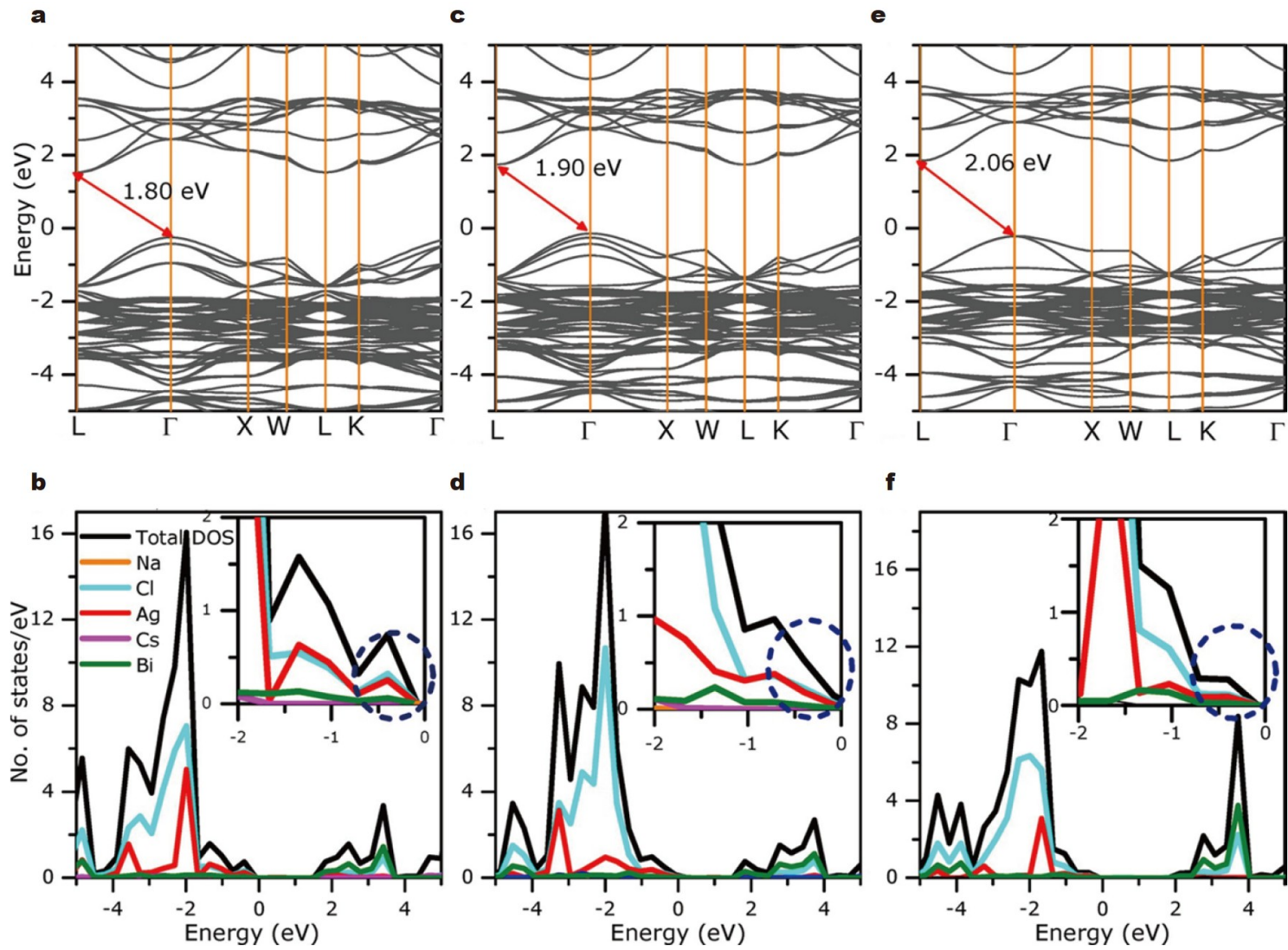

Figure 6 (a-f) Calculated electronic band structures and phonon density of states (PDOSs) for $\mathrm{Cs}_{2} \mathrm{Na}_{x} \mathrm{Ag}_{1-x} \mathrm{BiCl}_{6}$ at different values of $x$ : (a, b) $x=$ 0.25, (c, d) $x=0.50$, (e, f) $x=0.75$. Reprinted with permission from Ref. [59]. Copyright 2019, the American Chemical Society.

electron and hole wave functions were separated, reducing the probability of radiative transitions [62]. Locardi et al. [63] incorporated $\mathrm{Bi}$ into $\mathrm{Cs}_{2} \mathrm{Ag}_{1-x} \mathrm{Na}_{x} \mathrm{InCl}_{6}$ to produce $\mathrm{BiCl}_{6}$ states below the CBM. In contrast, in a Narich environment, localized $\mathrm{AgCl}_{6}$ energy levels would be above the VBM. Therefore, in the presence of sufficient $\mathrm{Na}$, the PL was enhanced through trapped emission occurring between states in $\left[\mathrm{BiCl}_{6}\right]$ and $\left[\mathrm{AgCl}_{6}\right]$ octahedra. In addition, $\mathrm{Ag}$ doping in $\mathrm{Cs}_{2} \mathrm{NaInCl}_{6}$ broke the darkstate self-trapped exciton transition, producing bright yellow PL (PLQY of 31\%) [64]. $\mathrm{Cs}_{2} \mathrm{AgInCl}_{6}$ exhibited a large direct bandgap, while $\mathrm{Cs}_{2} \mathrm{AgSbCl}_{6}$ presented an indirect bandgap. Tran et al. [65] reported that for $\mathrm{Cs}_{2} \mathrm{AgSb}_{x} \mathrm{In}_{1-x} \mathrm{Cl}_{6}$, the VBM increased owing to contributions from the $\mathrm{Sb} 5 \mathrm{~s}^{2}$ state, while the CBM was lowered because of contributions from the In $5 s^{0}$ and $\mathrm{Sb}$ $5 p$ states (Fig. 7b). This explained the transition from the indirect to direct bandgap at $x=0.4$. Moreover, the bandgap of $\mathrm{Cs}_{2} \mathrm{AgIn}_{x} \mathrm{Bi}_{1-x} \mathrm{Cl}_{6}(x=0,0.25,0.5,0.75$, and $0.9)$ was also tuned from indirect to direct [66,67]; as such, $\mathrm{Cs}_{2} \mathrm{AgIn}_{x} \mathrm{Bi}_{1-x} \mathrm{Cl}_{6}$ exhibited dual emission. Purple emission (highest PLQY of 36.6\%) originated from the indirect bandgap band edge and orange emission was produced upon doping with In (Fig. $7 \mathrm{c}-\mathrm{e}$ ) [66]. $\mathrm{In}^{3+} \mathrm{can}$ be replaced by doping the $\mathrm{Cs}_{2} \mathrm{AgInCl}_{6}$ lattice with $\mathrm{Yb}^{3+}$ and $\mathrm{Er}^{3+}$. The characteristic $\mathrm{f}-\mathrm{f}$ transition emissions were observed in the infrared region at 996 and $1537 \mathrm{~nm}$ for the $\mathrm{Yb}^{3+}$ and $\mathrm{Er}^{3+}$ dopants [68].

\section{$\mathrm{Bi}, \mathrm{Sb}(\mathrm{III})$-based $\mathrm{A}_{3} \mathrm{~B}_{2} \mathrm{X}_{9}$ layered perovskites}

The excellent properties of lead-based perovskites stem from the anti-bonding state formed by the coupling of $s$ orbital of $\mathrm{Pb}$ and $\mathrm{p}$ orbital of halogen which reduces the ionization energy and allows formation of the conduction band. Elements in the IVA group of the periodic table, which possess the same outermost $\mathrm{s}$ orbital and similar atomic weights as $\mathrm{Pb}$, include $\mathrm{Bi}$ and $\mathrm{Sb}$. However, $\mathrm{Bi}$ and $\mathrm{Sb}$ usually exhibit trivalent states; therefore, when these elements are employed in perovskites, the structural formula changes from $\mathrm{APbX}_{3}$ to $\mathrm{A}_{3}(\mathrm{Bi} / \mathrm{Sb})_{2} \mathrm{X}_{9}$ to maintain 

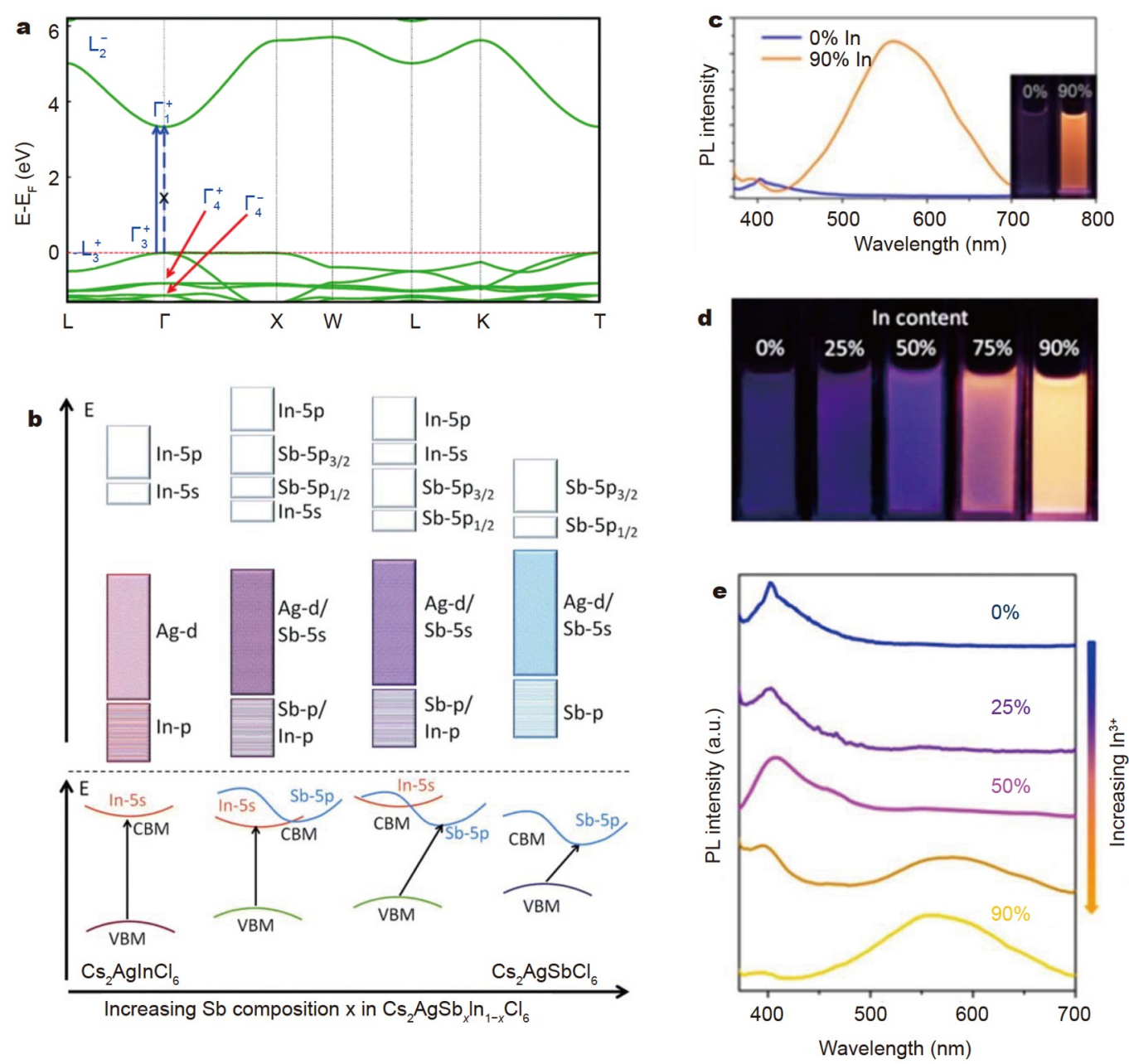

Figure 7 (a) Electronic band structure of $\mathrm{Cs}_{2} \mathrm{AgInCl}_{6}$. Reprinted with permission from Ref. [40]. Copyright 2017, the Royal Society of Chemistry. (b) Schematic of the bonding and anti-bonding bands in $\mathrm{Cs}_{2} \mathrm{AgSb}_{x} \mathrm{In}_{1-x} \mathrm{Cl}_{6}$ (upper part) and the proposed band diagram (lower part). Reprinted with permission from Ref. [65]. Copyright 2017, the Royal Society of Chemistry. (c) PL spectra for $\mathrm{Cs}_{2} \mathrm{AgIn}_{x} \mathrm{Bi}_{1-x} \mathrm{Cl}_{6}(x=0$ and 0.9) NCs. Inset: digital image showing the PL emission of $\mathrm{Cs}_{2} \mathrm{AgIn}_{x} \mathrm{Bi}_{1-x} \mathrm{Cl}_{6} \mathrm{NCs}\left(x=0\right.$ and 0.9). (d) Digital photographs of the PL emission for $\mathrm{Cs}_{2} \mathrm{AgIn}_{x} \mathrm{Bi}_{1-x} \mathrm{Cl}_{6} \mathrm{NCs}(x=0$, $0.25,0.5,0.75$, and 0.9). (e) PL spectra for $\mathrm{Cs}_{2} \mathrm{AgIn}_{x} \mathrm{Bi}_{1-x} \mathrm{Cl}_{6} \mathrm{NCs}(x=0,0.25,0.5,0.75,0.9)$. (c-e) are reprinted with permission from Ref. [66]. Copyright 2018, the American Chemical Society.

charge balance. This arrangement usually produces two types of structures: a two-dimensional layered structure with $\left[\mathrm{BX}_{6}\right]$ as the primary unit, and a zero-dimensional structure with $\left[\mathrm{B}_{2} \mathrm{X}_{9}\right]$ as the primary unit. The two-dimensional structure exhibits a direct bandgap, with superior electron and hole mobilities and a higher defect tolerance compared with those of the zero-dimensional structure.

\section{Bi(III)-based $A_{3} B_{2} X_{9}$ layered perovskites}

The structure of $\mathrm{A}_{3} \mathrm{Bi}_{2} \mathrm{X}_{9}$ perovskites is related to the Asite cation and the halogen element. The structure of layered $\mathrm{A}_{3} \mathrm{~B}_{2} \mathrm{X}_{9}$ can be obtained by removing the $\left[\mathrm{BX}_{6}\right]$ octahedra from every third layer of the three-dimensional
$\mathrm{ABX}_{3}$ structure along the $<111>$ direction. $\mathrm{Rb}_{3} \mathrm{Bi}_{2} \mathrm{I}_{9}$ exhibits a two-dimensional layered structure and belongs to the $P 2_{1} / n$ space group. As the atomic radius of $\mathrm{Rb}$ is smaller than that of $\mathrm{Cs}, \mathrm{Cs}_{3} \mathrm{Bi}_{2} \mathrm{I}_{9}$ presents a zero-dimensional dimer structure, belonging to the $\mathrm{PG}_{3} / m m c$ space group. Its structural unit is composed of a $\left[\mathrm{Bi}_{2} \mathrm{I}_{9}\right]^{3-}$ anion cluster. The independent $\left[\mathrm{Bi}_{2} \mathrm{I}_{9}\right]^{3-}$ anion cluster comprises two $\left[\mathrm{BiI}_{6}\right]^{-}$octahedra face-to-face (Fig. 8a). Similarly, in $\mathrm{Cs}_{3} \mathrm{Bi}_{2} \mathrm{X}_{9}$, when $\mathrm{X}=\mathrm{I}$ and $\mathrm{Br}$, a zero-dimensional and a two-dimensional structure, respectively, are formed. For the layered compounds, direct bandgaps of $2.17 \mathrm{eV}$ $\left(\mathrm{K}_{3} \mathrm{Bi}_{2} \mathrm{I}_{9}\right)$ or $2.16 \mathrm{eV}\left(\mathrm{Rb}_{3} \mathrm{Bi}_{2} \mathrm{I}_{9}\right)$ were obtained from the theoretical Heyd-Scuseria-Ernzerhof (HSE) and spinorbit coupling (SOC) calculations. The lowest conduc- 

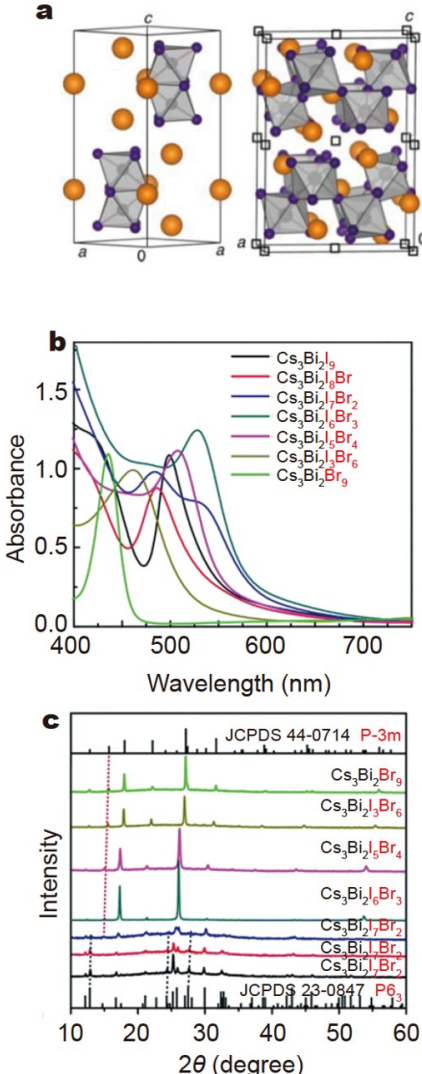
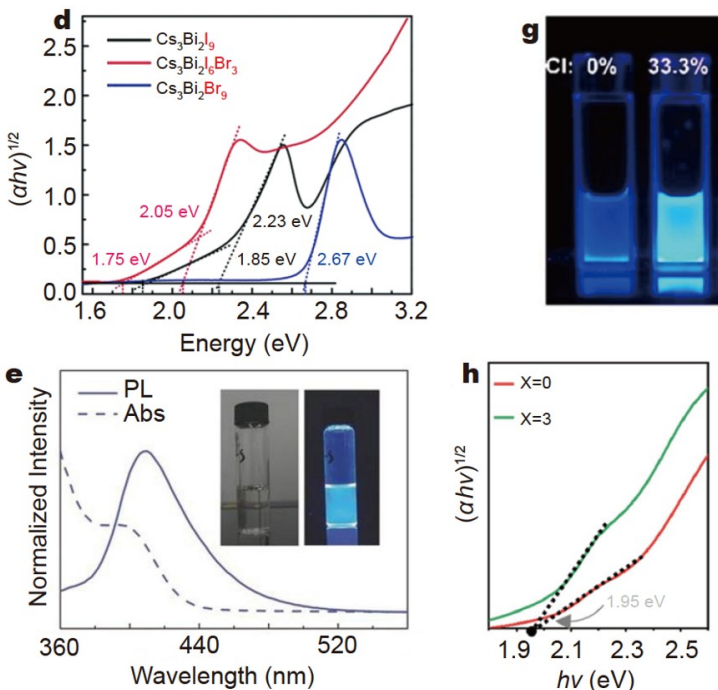

$\mathbf{f}$

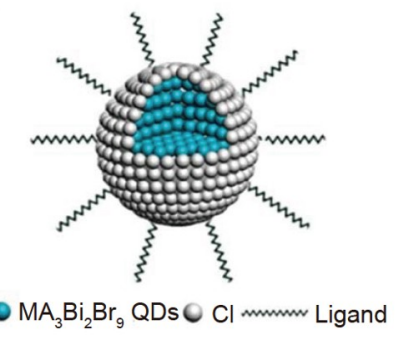

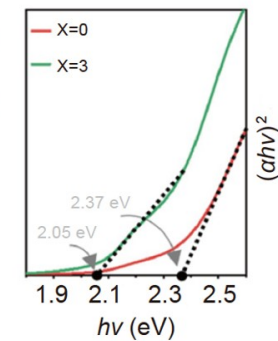
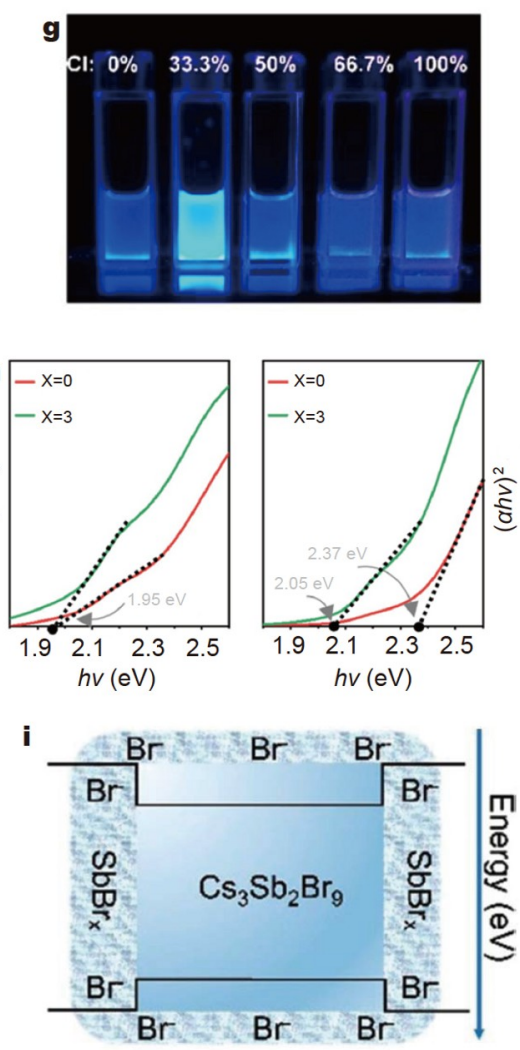

Figure 8 (a) Crystal structures of $\mathrm{Cs}_{3} \mathrm{Bi}_{2} \mathrm{I}_{9}$ (left) and $\mathrm{Rb}_{3} \mathrm{Bi}_{2} \mathrm{I}_{9}$ (right). Reprinted with permission from Ref. [69]. Copyright 2015, the American Chemical Society. (b) Absorption spectra for $\mathrm{Cs}_{3} \mathrm{Bi}_{2} \mathrm{I}_{x} \mathrm{Br}_{9-x}$ films. (c) X-ray diffraction (XRD) patterns for $\mathrm{Cs}_{3} \mathrm{Bi}_{2} \mathrm{I}_{9-x} \mathrm{Br}_{x}$ films. (d) Tauc plots for $\mathrm{Cs}_{3} \mathrm{Bi}_{2} \mathrm{I}_{9}, \mathrm{Cs}_{3} \mathrm{Bi}_{2} \mathrm{I}_{6} \mathrm{Br}_{3}$, and $\mathrm{Cs}_{3} \mathrm{Bi}_{2} \mathrm{Br}_{9}$ films. (b-d) are reprinted with permission from Ref. [70]. Copyright 2019, the Royal Society of Chemistry. (e) Absorption and PL spectra for $\mathrm{Cs}_{3} \mathrm{Bi}_{2} \mathrm{Br}_{9}$ QDs. Insets: digital images of the QD solution in ambient light and under illumination using a 325-nm UV lamp. Reprinted with permission from Ref. [75]. Copyright 2018, Wiley. (f) Model of Cl-passivated $\mathrm{MA}_{3} \mathrm{Bi}_{2} \mathrm{Br}_{9}$ QDs. (g) Digital photographs of $\mathrm{MA}_{3} \mathrm{Bi}_{2} \mathrm{Cl}_{x} \mathrm{Br}_{9-x}$ QD solutions under illumination using a 325-nm UV lamp. (f) and (g) are reprinted with permission from Ref. [79]. Copyright 2018, the American Chemical Society. (h) Tauc plots for $\mathrm{Cs}_{3} \mathrm{Sb}_{2} \mathrm{I}_{9}$ (left) and $\mathrm{Cs}_{3} \mathrm{Sb}_{2} \mathrm{Cl}_{3} \mathrm{I}_{6}$ (right). Reprinted with permission from Ref. [84]. Copyright 2020, Elsevier. (i) Proposed band structure diagram for $\mathrm{Cs}_{3} \mathrm{Sb}_{2} \mathrm{Br}_{9}$ QDs. Reprinted with permission from Ref. [87]. Copyright 2017, the American Chemical Society.

tion-band dispersion was moderate, while the highest valence band was extremely flat, indicating that the effective mass of electrons was lower than that of holes. Moreover, the high Born effective charges induced by the instability of the $\mathrm{Bi}^{3+} 6 \mathrm{~s}^{2}$ lone electron pair suggested potentially higher carrier mobilities [69].

$\mathrm{Yu}$ et al. [70] synthesized a series of $\mathrm{Cs}_{3} \mathrm{Bi}_{2} \mathrm{I}_{9-x} \mathrm{Br}_{x}$ thin films. As $x$ increased from 0 to 9 , the absorption edge shifted from 556 to $580 \mathrm{~nm}$ and then returned to $475 \mathrm{~nm}$. The absorption spectrum of $\mathrm{Cs}_{3} \mathrm{Bi}_{2} \mathrm{I}_{7} \mathrm{Br}_{2}$ displayed two peaks at $\sim 480$ and $580 \mathrm{~nm}$, indicating that two-phase separation occurred (Fig. 8b). From theoretical calculations and experimental characterization, when $x=3$, $\mathrm{Cs}_{3} \mathrm{Bi}_{2} \mathrm{I}_{9-x} \mathrm{Br}_{x}$ was completely transformed from the $\mathrm{P6}_{3} / m m c$ to the $P 3 m$ phase. $\mathrm{Cs}_{3} \mathrm{Bi}_{2} \mathrm{I}_{6} \mathrm{Br}_{3}$ exhibited the narrowest bandgap of $2.05 \mathrm{eV}$, significantly lower than that of $\mathrm{Cs}_{3} \mathrm{Bi}_{2} \mathrm{I}_{9}(2.23 \mathrm{eV}$; Fig. $8 \mathrm{c}$ and d). In addition, the $\mathrm{Cs}_{3} \mathrm{Bi}_{2} \mathrm{I}_{6} \mathrm{Br}_{3}$ film possessed larger crystal grains and presented a higher crystallinity, beneficial for photovoltaic applications. Iodine incorporation in $\mathrm{Cs}_{3} \mathrm{Bi}_{2} \mathrm{Cl}_{9}$ caused the structure to transform from one-dimensional chains to a two-dimensional vacancy-ordered structure [71]. The two-dimensional structure showed a larger energy band dispersion bonding strength. Iodine doping increased the anti-bonding energy of the $\mathrm{Bi} s$ and $\mathrm{Cl} \mathrm{p}$ orbitals in the valence band and reduced the bandgap. $\left(\mathrm{NH}_{4}\right)_{3} \mathrm{Bi}_{2} \mathrm{I}_{9}$ powder sample presented a direct bandgap of $2.04 \mathrm{eV}$ [72]. Single-crystal $\left(\mathrm{NH}_{4}\right)_{3} \mathrm{Bi}_{2} \mathrm{I}_{9}$ was easily grown in a lowtemperature solution, and exhibited an anisotropic response to X-ray irradiation [73].

A self-trapping state was present in $\mathrm{Cs}_{3} \mathrm{Bi}_{2} \mathrm{Br}_{9}$ QDs, which lowered the PLQY. Yang et al. [74] added OA 
during the preparation process to passivate the surface defects, improving the PLQY to $4.5 \%$. Leng et al. [75] (Fig. 8e) used ethanol as an anti-solvent to prepare $\mathrm{Cs}_{3} \mathrm{Bi}_{2} \mathrm{Br}_{9}$ QDs that presented blue emission at $410 \mathrm{~nm}$ with a PLQY of $19.4 \%$. Cao et al. [76] used $\gamma$-butyrolactone (GBL) as a precursor solvent to synthesize $\mathrm{Cs}_{3} \mathrm{Bi}_{2} \mathrm{Br}_{9}$ QDs. GBL possesses a small Gutmann donor number, allowing effective combination of the metal cation and the halogenated ion, thereby controlling the crystallization process precisely. Tetrabutylammonium bromide (TBABr) was also added to a precursor solution. The bromide ions in $\mathrm{TBABr}$ were involved in the formation of the $\left[\mathrm{BiBr}_{6}\right]$ octahedra, enabling attachment of alkyl chains to the QD surface. All these strategies improved the PLQY to approximately $40 \% . \mathrm{Cs}_{3} \mathrm{Bi}_{2} \mathrm{Br}_{9}$ nanoplatelets of size $60-250 \mathrm{~nm}$ were quantum confined, such that their PL peak was blue-shifted. Moreover, a sharp exciton peak was observed, in contrast to $\mathrm{Cs}_{3} \mathrm{Bi}_{2} \mathrm{Br}_{9}$ SCs [77].

$\mathrm{MA}_{3} \mathrm{Bi}_{2} \mathrm{Br}_{9}$ QDs were dominated by exciton recombination with a PLQY of $12 \%$ [78]. Because the $\mathrm{MA}_{3} \mathrm{Bi}_{2} \mathrm{Br}_{9}$ and $\mathrm{MA}_{3} \mathrm{Bi}_{2} \mathrm{Cl}_{9}$ structures were incompatible, Leng et al. [79] added $\mathrm{Cl}^{-}$in the synthesis of $\mathrm{MA}_{3} \mathrm{Bi}_{2} \mathrm{Br}_{9}$ QDs. The $\mathrm{Cl}^{-}$attached to the surface of $\mathrm{MA}_{3} \mathrm{Bi}_{2} \mathrm{Br}_{9}$ QDs, thus passivating them. At a $\mathrm{Cl}$ content of $33.3 \%$, the timeresolved PL spectra of the QDs could be fitted using a single exponential function, indicating that perfect surface passivation was achieved, with a PLQY of $54.1 \%$ (Fig. 8f and g). $\mathrm{FA}_{3} \mathrm{Bi}_{2} \mathrm{Br}_{9}$ QDs synthesized by a ligandassisted re-precipitation method presented a relatively large exciton binding energy with a direct bandgap of $2.87 \mathrm{eV}$. This was due to the strong quantum confinement effect induced by passivating the QDs surface with OAm and OA ligands, suggesting that this material could be used in LEDs [80].

Bi-based perovskites exhibit good stabilites. $\mathrm{Cs}_{3} \mathrm{Bi}_{2} \mathrm{Br}_{9}$ QDs retained $80 \%$ of their PL intensity after $78 \mathrm{~h}$ of continuous irradiation by ultraviolet (UV) light, demonstrating their excellent light stability. In addition, the $\mathrm{BiOBr}$ generated when a proper amount of water was added to an ethanol solution of $\mathrm{Cs}_{3} \mathrm{Bi}_{2} \mathrm{Br}_{9}$ QDs and passivated the surface defects of the QDs, almost doubling their PL intensity [75]. The addition of a small amount of ethanol to the $\mathrm{MA}_{3} \mathrm{Bi}_{2} \mathrm{Br}_{9}$ QD solution had little impact on their PL properties and would thus benefit the fabrication of the top organic electron (hole) transport layer in LEDs [78].

$S b(I I I)$-based $A_{3} B_{2} X_{9}$ layered perovskites

$\mathrm{Sb}$ is located in the same main group of the periodic table as $\mathrm{Bi}$, but it possesses a smaller relative atomic mass. In addition to cation and halide ion selection, numerous synthetic methods allow the transformation of $\mathrm{A}_{3} \mathrm{Sb}_{2} \mathrm{X}_{9}$ from a zero-dimensional to a two-dimensional structure. For example, Saparov et al. [81] controlled the annealing temperature during the preparation of a $\mathrm{Cs}_{3} \mathrm{Sb}_{2} \mathrm{I}_{9}$ film. Giesbrecht et al. [82] employed $\mathrm{Sb}(\mathrm{OAc})_{3}$ (OAc : $\mathrm{CH}_{3} \mathrm{COO}^{-}$) as an antimony precursor. As every antimony atom coordinated with seven oxygen atoms in $\mathrm{Sb}(\mathrm{OAc})_{3}$, such that adjacent $\mathrm{Sb}$ atoms were $4.9 \AA$ apart and thereby producing a structure larger than that of $\mathrm{SbI}_{3}$. Layered $\mathrm{MA}_{3} \mathrm{Sb}_{2} \mathrm{I}_{9}$ was formed after the addition of MAI. Like Bi, replacing the iodide ion in $\mathrm{MA}_{3} \mathrm{Sb}_{2} \mathrm{I}_{9}$ with chloride allowed a dimensional structure change $[83,84]$. In addition, choosing a cation with a small radius led to dimer phase transformation to a layered phase [85]. The modification of a layered $\mathrm{Cs}_{3} \mathrm{Sb}_{2} \mathrm{I}_{9}$ film produced a direct bandgap of $2.05 \mathrm{eV}$ [81], while dimer-phase $\mathrm{Cs}_{3} \mathrm{Sb}_{2} \mathrm{I}_{9}$ displayed an indirect transition at $1.95 \mathrm{eV}$ as well as a direct transition at $2.37 \mathrm{eV}$. After chloride substitution, $\mathrm{Cs}_{3} \mathrm{Sb}_{2} \mathrm{Cl}_{3} \mathrm{I}_{6}$ exhibited a smaller direct bandgap of $2.05 \mathrm{eV}$, close to the indirect bandgap (Fig. 8h) [84]. $\mathrm{Cs}_{3} \mathrm{Sb}_{2} \mathrm{I}_{9} \mathrm{NCs}$ presented a sharp emission peak in the red-yellow region with many-body exciton interactions and a high absorption cross-section of $1.1 \times 10^{-15} \mathrm{~cm}^{2}$ [86]. Zhang et al. [87] reported that $\mathrm{Cs}_{3} \mathrm{Sb}_{2} \mathrm{Br}_{9}$ QDs exhibited a high exciton binding energy of $530 \mathrm{meV}$, and that excess Br effectively passivated the surface defect states, resulting in a high PLQY of $46 \%$ (Fig. 8i). Compared with bulk SCs, the emission peak of $\mathrm{Rb}_{3} \mathrm{Sb}_{2} \mathrm{I}_{9}$ nanoparticles was blue-shifted with a smaller FWHM of $21 \mathrm{~nm}$, which is the narrowest emission peak reported to date for lead-free perovskite materials [88].

\section{Two-dimensional Sn(II)-based perovskites}

Three-dimensional tin perovskites like $\mathrm{MASnI}_{3}$ can be self-doped (p-type) by the easy oxidation of $\mathrm{Sn}^{2+}$ to $\mathrm{Sn}^{4+}$, exhibiting metal conductivity [89-91], which is unfavorable for device performance. Mitzi et al. [92] reported that the metal conductivity of a three-dimensional organic tin halide perovskite could be suppressed by reducing the crystal structure dimension. Two-dimensional tin perovskites are composed of organic and inorganic components, allowing additional structural variability, greater anisotropy, and unique optical and electrical properties.

Compared with the three-dimensional tin(II) perovskite, the two-dimensional tin(II) perovskite $(\mathrm{PEA})_{2} \mathrm{SnI}_{4} \quad\left(\mathrm{PEA}=\mathrm{C}_{6} \mathrm{H}_{5} \mathrm{CH}_{2} \mathrm{CH}_{2} \mathrm{NH}_{3}{ }^{+}\right)$exhibited a smaller bandgap of $\sim 1.26 \mathrm{eV}$ due to the quantum con- 
finement effect. The confinement of electrons and holes in the two-dimensional structure increased the recombination probability; therefore, $(\mathrm{PEA})_{2} \mathrm{SnI}_{4}$ presented a longer PL decay lifetime (Fig. 9a) [93]. Zhang et al. [94] reported that the two-dimensional structure formed by $\mathrm{C}_{18} \mathrm{H}_{35} \mathrm{NH}_{3}{ }^{+}\left(\mathrm{OAm}^{+}\right)$and $\left[\mathrm{SnBr}_{6}\right]$ octahedra in $(\mathrm{OAm})_{2}{ }^{-}$ $\mathrm{SnBr}_{4}$ impeded the formation of electron bands between
$\left[\mathrm{SnBr}_{6}\right]$ units, resulting in strong Stokes shift and high PLQY (Fig. 9b and c). $\mathrm{Bi}^{3+}$ and $\mathrm{Sn}^{2+}$ possess similar ionic radii, and $\mathrm{Bi}$ doping did not change the phase in $\mathrm{PEA}_{2}$ $\mathrm{SnBr}_{4}$ [95]. Doping with $0 \%-20 \% \mathrm{Bi}$ had little effect on the bandgap. Bi-doped $\mathrm{PEA}_{2} \mathrm{SnBr}_{4}$ produced non-intrinsic self-trapping excitons as a result of local lattice inhomogeneity. Self-trapping exciton emission peaks
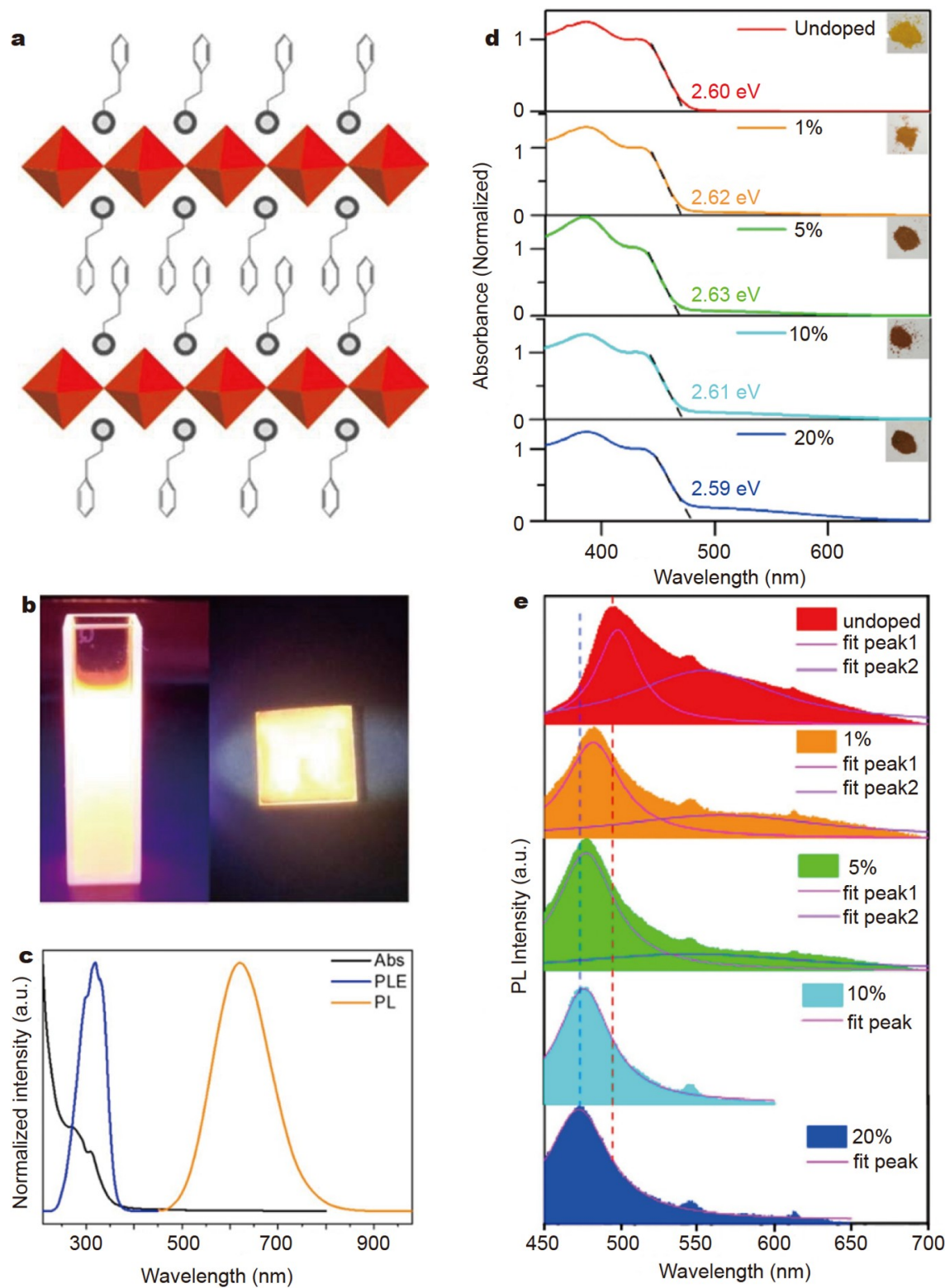

Figure 9 (a) Crystal structure of (PEA) $\mathrm{SnI}_{x} \mathrm{Br}_{4-x}$. Reprinted with permission from Ref. [93]. Copyright 2017, the American Chemical Society. (b) Digital photograph of an $(\mathrm{OAm})_{2} \mathrm{SnBr}_{4}$ perovskite colloidal suspension (left) and film (right) under illumination using a UV light. (c) Normalized absorption, PL excitation, and PL spectra for the $(\mathrm{OAm})_{2} \mathrm{SnBr}_{4}$ perovskite film. (b) and (c) are reprinted with permission from Ref. [94]. Copyright 2018, the American Chemical Society. (d) Optical diffuse reflectance spectra and (e) room-temperature PL spectra for Bi-doped $\mathrm{PEA}_{2} \mathrm{SnBr}_{4}$ containing different $\mathrm{Bi}$ concentrations ranging from $0 \%$ to $20 \%$. Insets show corresponding digital photographs of the powders. Reprinted with permission from Ref. [95]. Copyright 2019, Elsevier. 
were observed in addition to the free exciton emission (Fig. 9d and e). In contrast to organic ammonium ion, the hydrogen bonding between the imidazole derivative and $\left[\mathrm{SnI}_{6}\right]$ octahedra in $\mathrm{Bn}_{2} \mathrm{SnI}_{4}(\mathrm{Bn}=$ benzimidazolium) was symmetric, resulting in a small distortion of the $\left[\mathrm{SnI}_{6}\right]$ octahedra and a smaller direct bandgap of $1.8 \mathrm{eV}$. The partial substitution of $\mathrm{Pb}$ with $\mathrm{Sn}$ formed a solid solution and allowed adjustment of the bandgap in the visible wavelength range [96]. The low PLQY of two-dimensional Sn perovskites was attributed to strong excitonphonon interactions [97]. Different cations can change the material stability by interacting with $\left[\mathrm{SnX}_{6}\right]$ units. When close aligned bulky stilbene derivatives (2-(4-(3fluoro)stilbenyl) ethanammonium iodide (FSAI)) were used as organic cations, unique face-to-face interactions were present, such as face-to-face hydrogen bonding, $\mathrm{CH} \cdots \mathrm{X}$ hydrogen bonding, and interlayer F...F interac- tions. These generated superior air and water stability compared with those of three-dimensional Sn-based perovskites [98].

\section{$\mathrm{Bi}, \mathrm{Sb}$ (III)-based $\mathrm{A}_{3} \mathrm{~B}_{\mathbf{2}} \mathrm{X}_{\mathbf{9}}$ dimer perovskites}

Zero-dimensional structures are also suitable for $\mathrm{Bi}$ and $\mathrm{Sb}$ substitution. For example, $\mathrm{Cs}_{3} \mathrm{Bi}_{2} \mathrm{I}_{9}$ consists of $\left[\mathrm{Bi}_{2} \mathrm{I}_{9}\right]$ clusters surrounded by $\mathrm{Cs}$ cations and belongs to the $\mathrm{P6}_{3} / \mathrm{mmc}$ space group, as shown in Fig. 10a [99]. A $\mathrm{MA}_{3} \mathrm{Bi}_{2} \mathrm{I}_{9}$ film exhibited a direct bandgap of $2.9 \mathrm{eV}$ and an exciton binding energy of $400 \mathrm{meV}$. Phonon density of states (PDOSs) results showed two separate conduction bands with a gap of $0.5 \mathrm{eV}$. The lower conduction band extended the bismuth and iodide states, while the higher conduction band was primarily composed of Cs-I hybrid states. The effective masses of electrons and holes were obtained based on the band structures of the VBM and
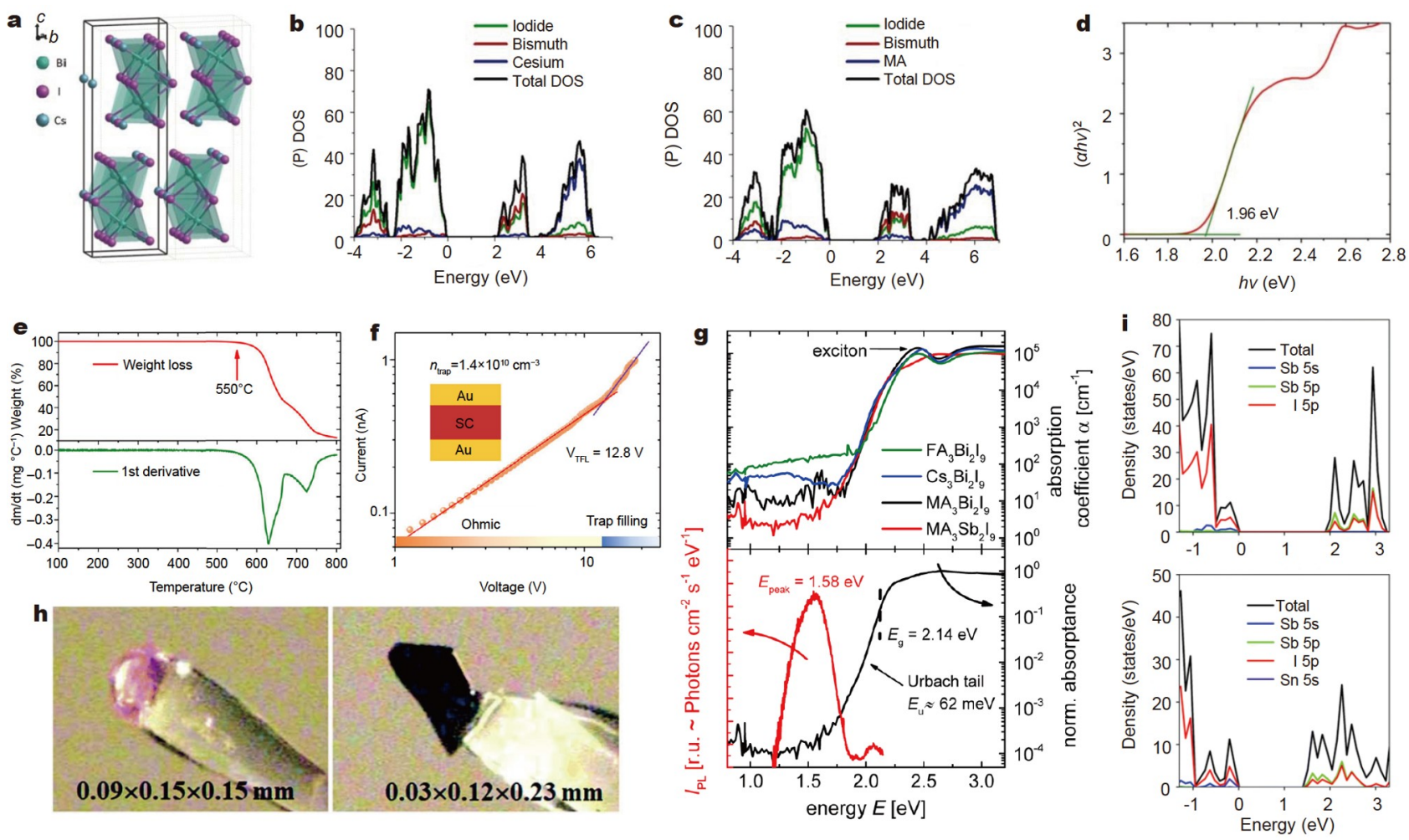

Figure 10 (a) Crystal structure of $\mathrm{Bi}, \mathrm{Sb}$ (III)-based $\mathrm{A}_{3} \mathrm{~B}_{2} \mathrm{X}_{9}$ dimer-phase perovskites. Reprinted with permission from Ref. [99]. Copyright 2015, Wiley. Calculated density of states (DOSs) for (b) $\mathrm{Cs}_{3} \mathrm{Bi}_{2} \mathrm{I}_{9}$ and (c) $\mathrm{MA}_{3} \mathrm{Bi}_{2} \mathrm{I}_{9}$ perovskites. Reprinted with permission from Ref. [100]. Copyright 2016, the American Chemical Society. (d) Tauc plot for $\mathrm{Cs}_{3} \mathrm{Bi}_{2} \mathrm{I}_{9}$. (e) Thermogravimetric analysis plot and first-order derivative for single-crystal $\mathrm{Cs}_{3} \mathrm{Bi}_{2} \mathrm{I}_{9}$. (f) Current-voltage curve for a hole-only $\mathrm{Cs}_{3} \mathrm{Bi}_{2} \mathrm{I}_{9}$ device. (d-f) are reprinted with permission from Ref. [101]. Copyright 2020, Springer Nature. (g) Upper part: photothermal deflection spectroscopy (PDS) measurements for Bi-based perovskites and $\mathrm{MA}_{3} \mathrm{Sb}_{2} \mathrm{I}_{9}$. Lower part: normalized absorptance of $\mathrm{MA}_{3} \mathrm{Sb}_{2} \mathrm{I}_{9}$ (from PDS) with the calculated Urbach tail energy indicated and the corresponding PL spectrum. Reprinted with permission from Ref. [103]. Copyright 2016, the American Chemical Society. (h) Digital photographs of $\mathrm{MA}_{3} \mathrm{Sb}_{2} \mathrm{I}_{9}$ (left) and Sn-doped $\mathrm{MA}_{3} \mathrm{Sb}_{2} \mathrm{I}_{9}$ (right). (i) Total DOS and partial DOS of intrinsic $\mathrm{MA}_{3} \mathrm{Sb}_{2} \mathrm{I}_{9}$ (upper part) and Sn-doped $\mathrm{MA}_{3} \mathrm{Sb}_{2} \mathrm{I}_{9}$ (lower part). (h) and (i) are reprinted with permission from Ref. [25]. Copyright 2019, the Royal Society of Chemistry. 
CBM (Fig. 10b and c) [100]. Zhang et al. [101] synthesized $\mathrm{Cs}_{3} \mathrm{Bi}_{2} \mathrm{I}_{9} \mathrm{SCs}$ with a bandgap of $1.96 \mathrm{eV}$ and superior thermal and moisture stabilities compared with those of $\mathrm{Pb}$-based two-dimensional perovskites. Furthermore, the trap density of $\mathrm{Cs}_{3} \mathrm{Bi}_{2} \mathrm{I}_{9}$ was $1.4 \times 10^{10} \mathrm{~cm}^{-3}$, considerably lower than those of common inorganic semiconductors, such as polysilicon, Cd, and Te (Fig. 10d-f). Pious et al. [102] employed benzylammonium as a cation. They observed that benzyl cation polarization reduced the dielectric mismatch between $\left[\mathrm{Bi}_{2} \mathrm{I}_{9}\right]$ and the organic cations.

Compared with Bi-based perovskites, the absorption spectrum of $\mathrm{MA}_{3} \mathrm{Sb}_{2} \mathrm{I}_{9}$ did not display obvious exciton absorption, indicating a lower exciton energy. $\mathrm{MA}_{3} \mathrm{Sb}_{2} \mathrm{I}_{9}$ exhibited an absorption coefficient above $10^{5} \mathrm{~cm}^{-1}$ with a bandgap of $2.14 \mathrm{eV}$. The weak PL was located at $\sim 560 \mathrm{meV}$, away from the band edge, suggesting radiative recombination involving sub-bandgap states. This was further supported by the relatively high Urbach tail energy (62 meV) (Fig. 10g) [103]. Ju et al. [25] successfully doped single-crystal $\mathrm{MA}_{3} \mathrm{Sb}_{2} \mathrm{I}_{9}$ with $\mathrm{Sn}$, where $\mathrm{Sb}$ was replaced by $S n$ in the unit cell. The upper valence band of $\mathrm{Sn}$-doped $\mathrm{MA}_{3} \mathrm{Sb}_{2} \mathrm{I}_{9}$ comprised the $\mathrm{Sn} 5 \mathrm{~s}$ and I $5 \mathrm{p}$ orbital bonding states, significantly reducing the bandgap. A substantially red-shifted absorption peak at $296 \mathrm{~nm}$ was observed for Sn-doped $\mathrm{MA}_{3} \mathrm{Sb}_{2} \mathrm{I}_{9}$ and the carrier mobility was approximately doubled (Fig. 10h and i). Moreover, adding $\mathrm{HI}$ to $\mathrm{MA}_{3} \mathrm{Sb}_{2} \mathrm{I}_{9}$ films allowed valence-band tuning and improved the morphologies of the films [104,105]. Cation choice also influences the properties of $\mathrm{A}_{3} \mathrm{Sb}_{2} \mathrm{X}_{9}$. For example, the ordered-disordered transformation that occurs in $\mathrm{N}$-methylpyrrolidinium significantly affected the ferroelectricity of ( $N$-methylpyrrolidinium $)_{3} \mathrm{Sb}_{2} \mathrm{Br}_{9}$ [106].

\section{$\mathrm{Sn}(\mathrm{IV})$-based $\mathrm{A}_{2} \mathrm{SnX}_{6}$ perovskites}

$\mathrm{Sn}(\mathrm{IV})$-based perovskites possess the chemical formula $\mathrm{A}_{2} \mathrm{SnX}_{6}$. Their structure can be considered as the vacancyordered $\mathrm{ABX}_{3}$ structure with the adjacent $\mathrm{B}$ atoms removed. Zhou et al. [107] described the crystal structure of $\mathrm{Cs}_{2} \mathrm{SnI}_{6}$ (Fig. 11a). The isolated $\left[\mathrm{BX}_{6}\right]$ octahedron was bridged by $\mathrm{Cs}^{+}$, generating a quantum-confined structure, enhancing the PL. The stable tin(IV) oxidation state renders high symmetry, air stability, and excellent photoelectric properties of $\mathrm{A}_{2} \mathrm{Sn}(\mathrm{IV}) \mathrm{X}_{6}$ perovskites. Maughan et al. [108] compared a series of $\mathrm{A}_{2} \mathrm{SnI}_{6}$ compounds ( $\mathrm{A}=$ $\mathrm{Cs}^{+}, \mathrm{MA}^{+}$, or $\left.\mathrm{FA}^{+}\right)$. These three compounds exhibited the cubic space group structure shown in Fig. 11b. When the larger $\mathrm{MA}^{+}$and $\mathrm{FA}^{+}$ions were introduced at the A-site, a

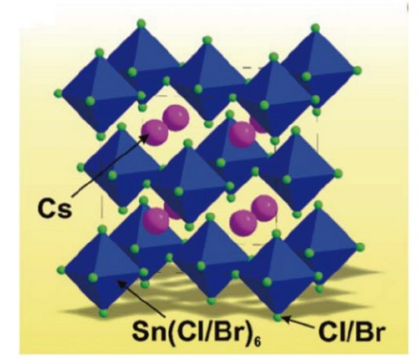

b

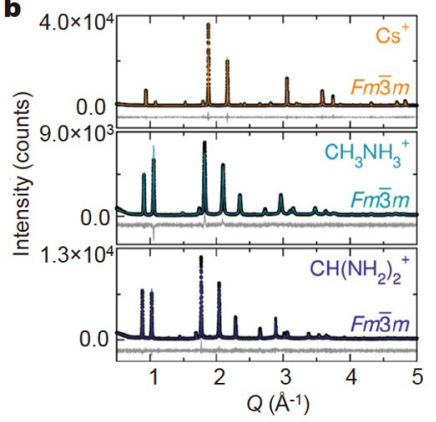

c

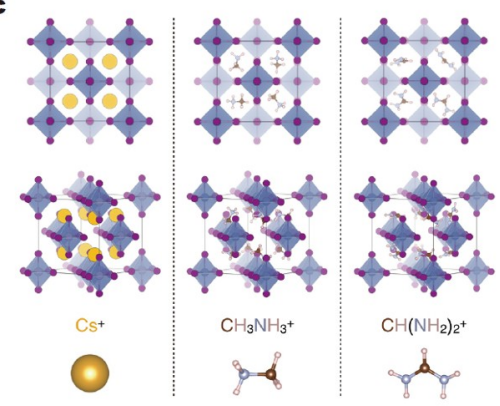

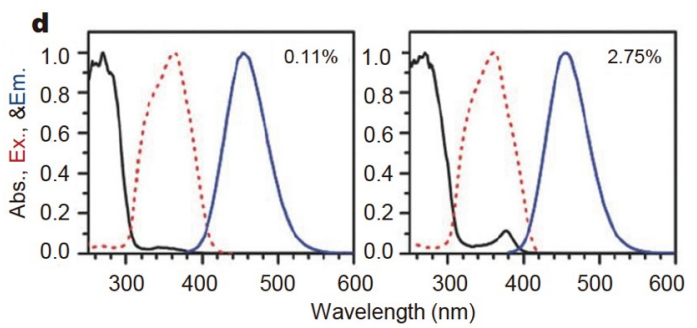
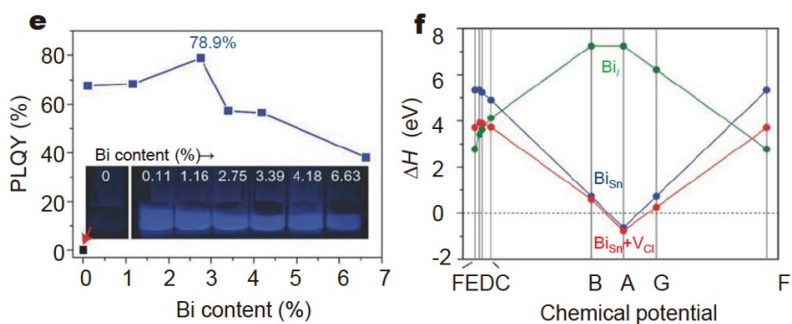

Figure 11 (a) Crystal structure of $\mathrm{A}_{2} \mathrm{Sn}(\mathrm{IV}) \mathrm{X}_{6}$. Reprinted with permission from Ref. [107]. Copyright 2019, Wiley. (b) XRD patterns for the $\mathrm{A}_{2} \mathrm{SnI} \mathrm{I}_{6}$ series $\left(\mathrm{A}=\mathrm{Cs}^{+}, \mathrm{MA}^{+}\right.$, or $\mathrm{FA}^{+}$). (c) Structures of $\mathrm{Cs}_{2} \mathrm{SnI}_{6}, \mathrm{MA}_{2} \mathrm{SnI}_{6}$, and $\mathrm{FA}_{2} \mathrm{SnI}_{6}$. (b) and (c) are reprinted with permission from Ref. [108]. Copyright 2018, the American Chemical Society. (d) Normalized absorbance (black), excitation (red), and emission (blue) spectra for the as-synthesized $\mathrm{Cs}_{2} \mathrm{SnCl}_{6}: 0.11 \% \mathrm{Bi}$ (left) and $\mathrm{Cs}_{2} \mathrm{SnCl}_{6}: 2.75 \% \mathrm{Bi}$ (right). (e) Room-temperature PLQYs of the $\mathrm{Cs}_{2} \mathrm{SnCl}_{6}: x \mathrm{Bi}$ samples $(x=0 \%, 0.11 \%, 1.16 \%, 2.75 \%$, $3.39 \%, 4.18 \%$, and $6.63 \%$ ). Inset: digital photographs of the $\mathrm{Cs}_{2} \mathrm{SnCl}_{6}: x \mathrm{Bi}$ samples under illumination using a $365 \mathrm{~nm} \mathrm{UV}$ light. (f) Calculated formation enthalpies $(\Delta H)$ of neutral $\mathrm{Bi}_{\mathrm{i}}, \mathrm{Bi}_{\mathrm{Sn}}$, and $\mathrm{Bi}_{\mathrm{S}_{\mathrm{n}}}+\mathrm{V}_{\mathrm{Cl}}$ as a function of the chemical potentials. (d-f) are reprinted with permission from Ref. [114]. Copyright 2018, Wiley. 
the volume of the unit cell and the I-I contact distance between the $\left[\mathrm{SnI}_{6}\right]$ octahedra increased, as shown in the refined structure (Fig. 11c). Funabiki et al. [109] reported that the structures of $\mathrm{MA}_{2} \mathrm{SnI}_{6}$ powder and film were consistent with the above results. Furthermore, the authors determined that the (111) plane was the most energy-stable surface. Maughan et al. [110] compared the aforementioned $\mathrm{A}_{2} \mathrm{SnI}_{6}$ series with $\mathrm{Rb}_{2} \mathrm{SnI}_{6}$. $\mathrm{Rb}_{2} \mathrm{SnI}_{6}$ possessed a tetragonal perovskite structure $(P 4 / m n c)$ at $295 \mathrm{~K}$ that was distorted to a low-symmetry monoclinic perovskite structure $\left(P 2_{1} / n\right)$ at $100 \mathrm{~K}$, while no temperaturedependent octahedral distortion was observed in $\mathrm{Cs}_{2} \mathrm{SnI}_{6}$. The tolerance factors $(t)$ of $\mathrm{Cs}_{2} \mathrm{SnI}_{6}, \mathrm{MA}_{2} \mathrm{SnI}_{6}, \mathrm{FA}_{2} \mathrm{SnI}_{6}$ and $\mathrm{Rb}_{2} \mathrm{SnI}_{6}$ were calculated to be $0.998,1.07,1.16$, and 0.959 , respectively.

$\mathrm{Cs}_{2} \mathrm{SnI}_{6}, \mathrm{MA}_{2} \mathrm{SnI}_{6}, \mathrm{FA}_{2} \mathrm{SnI}_{6}$, and $\mathrm{Rb}_{2} \mathrm{SnI}_{6}$ were considered n-type semiconductors. The Rb-substituted $\mathrm{Sn}(\mathrm{IV})$ perovskite had significantly lower carrier mobility than $\mathrm{Cs}_{2} \mathrm{SnI}_{6}$. In general, the electronic properties of vacancy-ordered double perovskites are determined by their lattice dynamics. Based on a geometric model of the perovskite tolerance factor, the interaction between octahedral tilt and charge transport in the $\mathrm{A}_{2} \mathrm{SnI}_{6}$ series was summarized. This was used to predict the charge transfer behavior in vacancy-ordered double perovskites. Materials with tolerance factors closer to 1 exhibited higher carrier mobilities. In the light of the abovementioned tolerance factors, $\mathrm{Cs}_{2} \mathrm{SnI}_{6}, \mathrm{MA}_{2} \mathrm{SnI}_{6}, \mathrm{FA}_{2} \mathrm{SnI}_{6}$, and $\mathrm{Rb}_{2} \mathrm{SnI}_{6}$ exhibited maximum carrier mobilities of approximately 9 , 2, 0.36 , and $0.22 \mathrm{~cm}^{2} \mathrm{~V}^{-1} \mathrm{~s}^{-1}$, respectively $[108,111]$.

The $\mathrm{Sn}(\mathrm{IV})$-based perovskite $\mathrm{A}_{2} \mathrm{SnX}_{6}$ exhibits better stability than the $\mathrm{Sn}(\mathrm{II})$-based perovskite. However, the reported PLQYs of these compounds are low. The PLQY of $\mathrm{Cs}_{2} \mathrm{SnI}_{6}$ was $0.48 \%$, considerably lower than those of lead-based perovskites [112]. Doping is an effective method to control the physical properties of metal halide perovskites and to confer new properties to the material [113]. Tan et al. [114] doped the vacancy-ordered double perovskite $\mathrm{Cs}_{2} \mathrm{SnCl}_{6}$ with $\mathrm{Bi}^{3+}$ and compared the $\mathrm{PL}$ performances of the samples containing different doping ratios. The results showed that the undoped sample presented no PL, while the PL performances of the doped samples were significantly improved. Fig. $11 \mathrm{~d}-\mathrm{g}$ show that the best doping ratio of Bi was $2.75 \%$, with a PL peak at $\sim 455 \mathrm{~nm}$; the material showed a PLQY of $78.9 \%$, close to those of lead-based perovskites [115]. Bi ions were incorporated at the $\mathrm{Sn}$ site in a $\mathrm{Cs}_{2} \mathrm{SnCl}_{6}$ matrix, as confirmed by material characterization and first-principles calculations. $A \mathrm{Bi}_{\mathrm{Sn}}+\mathrm{V}_{\mathrm{Cl}}$ defect complex was formed, resulting in strong blue emission. The basic properties of lead-free perovskites are summarized in Table 1.

\section{PHOTOELECTRIC DEVICE APPLICATIONS}

\section{Solar cells}

\section{Sn-based perovskite solar cells}

The radii of the IVA ions $\mathrm{Sn}^{2+}(1.35 \AA)$ and $\mathrm{Pb}^{2+}(1.49 \AA)$ are similar. Thus, significant lattice distortion does not occur when lead is replaced with tin in perovskite materials [116]. The optical bandgaps of tin-based perovskites are narrower than those of lead-based perovskites, indicating that the absorption wavelength of tin-based perovskites can range from 800 to $950 \mathrm{~nm}$ [51]. Extensive research on tin-based perovskite solar cells (PSCs) has been performed. In 2014, Hao et al. [117] used $\mathrm{MASnI}_{3}$ to prepare tin-based PSCs that achieved a PCE of $5.73 \%$. Koh et al. [118] employed $\mathrm{FASnI}_{3}$ with added $\mathrm{SnF}_{2}$ as a light-absorbing material in solar cells, realizing an efficiency of $2.10 \%$. Many methods to optimize the efficiency of solar cells by improving the perovskite absorber layer have been reported.

Ogomi et al. [119] introduced $\mathrm{SnI}_{2}$ to the $\mathrm{MAPbI}_{3}$ structure to prepare a $\mathrm{MASn}_{x} \mathrm{~Pb}_{1-x} \mathrm{I}_{3}$ perovskite. Optoelectronic devices prepared with this material exhibited a spectral response up to $1060 \mathrm{~nm}$ (Fig. 12a), a short-circuit current density $\left(J_{\mathrm{sc}}\right)$ of $20.04 \mathrm{~mA} \mathrm{~cm}^{-2}$, and a maximum PCE of $4.18 \%$. Hao et al. [120] prepared a series of $\mathrm{MASn}_{1-x} \mathrm{~Pb}_{x} \mathrm{I}_{3}$ perovskites with adjustable bandgaps of $1.17-1.55 \mathrm{eV}$, achieved by mixing tin and lead (Fig. 12b). Mixed tin-lead materials showed significantly improved carrier transport characteristics compared with $\mathrm{MAPbI}_{3}$ [121]. Lee et al. [122] observed that at a Sn content of $60 \%$ in the mixed tin-lead perovskite, carrier recombination was drastically weakened, the photoelectric output stability was enhanced, and the PCE of the device reached 13.4\% (Fig. 12c). Wang et al. [123] used a two-step solution method to prepare a dense $\mathrm{FA}_{0.7} \mathrm{MA}_{0.3} \mathrm{Sn}_{0.3} \mathrm{~Pb}_{0.7} \mathrm{I}_{3}$ film with a bandgap of $1.26 \mathrm{eV}$ on the hydrophobic holetransporting material, with a PCE of $13.6 \%$.

Hao et al. [124] reported the effect of the solvent in the crystallization process of $\mathrm{MASnI}_{3}$ films. When DMSO was used, a uniform, non-porous film was prepared, and the device exhibited a $J_{\mathrm{sc}}$ value of $21 \mathrm{~mA} \mathrm{~cm}^{-2}$. Weiss et al. [125] employed a two-step method, combined with vapor deposition, to synthesize a $\mathrm{MASnI}_{3}$ perovskite film that exhibited significantly enhanced chemical stability in air and under light illumination. Research on the interface between $\mathrm{MASnI}_{3}$ and $\mathrm{TiO}_{2}$ determined that the surface 
Table 1 Basic properties of lead-free perovskites

\begin{tabular}{|c|c|c|c|c|c|}
\hline & Dimensionality & Space group & Bandgap (eV) & Emission $(\mathrm{nm})$ & Ref. \\
\hline $\mathrm{CsSnBr}_{3}$ film & 3 & Pnma & - & 915 & [49] \\
\hline $\mathrm{CsSnI}_{3}$ film & 3 & Pnma & - & - & [49] \\
\hline $\mathrm{CsSnCl}_{3}$ film & 3 & $P m 3 m$ & - & 440 & [49] \\
\hline $\mathrm{CsSnI}_{3} \mathrm{SCs}$ & 3 & Pnma & 1.31 & 950 & {$[52]$} \\
\hline $\mathrm{MASnI}_{3}$ film & 3 & $P 4 m m$ & 1.3 & 970 & [125] \\
\hline $\mathrm{CsSnCl}_{3} \mathrm{NCs}$ & 3 & $P m 3 m$ & 2.8 & 470 & {$[38]$} \\
\hline $\mathrm{CsSnBr}{ }_{3} \mathrm{NCs}$ & 3 & Pnma & 1.8 & 675 & {$[38]$} \\
\hline $\mathrm{CsSnI}_{3} \mathrm{NCs}$ & 3 & Pnma & 1.3 & 880 & {$[38]$} \\
\hline $\mathrm{Cs}_{2} \mathrm{SnCl}_{6}$ powder & 0 & $P m 3 m$ & 4.6 & - & [136] \\
\hline $\mathrm{Cs}_{2} \mathrm{SnI}_{6}$ powder & 0 & $P m 3 m$ & 1.32 & 810 & [136] \\
\hline $\mathrm{Cs}_{2} \mathrm{SnI}_{6}$ film & 0 & $P m 3 m$ & 1.3 & - & [139] \\
\hline $\mathrm{Cs}_{3} \mathrm{Bi}_{2} \mathrm{I}_{9}$ powder & 0 & $P 6_{3} / m m c$ & 1.9 & - & [69] \\
\hline $\mathrm{Rb}_{3} \mathrm{Bi}_{2} \mathrm{I}_{9}$ powder & 2 & $P 2_{1} / n$ & 2.1 & - & [69] \\
\hline $\mathrm{Cs}_{3} \mathrm{Bi}_{2} \mathrm{I}_{9}$ film & 0 & $\mathrm{PG}_{3} / \mathrm{mmc}$ & 2.05 & 674 & [70] \\
\hline $\mathrm{Cs}_{3} \mathrm{Bi}_{2} \mathrm{Br}_{9}$ film & 2 & $P m$ & 2.23 & 470 & [70] \\
\hline $\mathrm{Cs}_{3} \mathrm{Bi}_{2} \mathrm{CI}_{9} \mathrm{SCs}$ & 1 & Pnma & 2.09 & - & [71] \\
\hline$\left(\mathrm{NH}_{4}\right)_{3} \mathrm{Bi}_{2} \mathrm{I}_{9} \mathrm{SCs}$ & 2 & $P 2_{1} / n$ & 1.46 & - & {$[72]$} \\
\hline $\mathrm{Cs}_{3} \mathrm{Bi}_{2} \mathrm{I}_{9}$ QDs & 0 & $\mathrm{~Pb}_{3} / \mathrm{mmc}$ & - & 393 & [75] \\
\hline $\mathrm{Cs}_{3} \mathrm{Bi}_{2} \mathrm{Br}_{9}$ QDs & 0 & $P 6_{3} / m m c$ & - & 410 & [75] \\
\hline $\mathrm{Cs}_{3} \mathrm{Bi}_{2} \mathrm{CI}_{9}$ QDs & 0 & $\mathrm{PG}_{3} / \mathrm{mmc}$ & - & 545 & [75] \\
\hline $\mathrm{Cs}_{3} \mathrm{Sb}_{2} \mathrm{I}_{9} \mathrm{NCs}$ & 2 & $P m 1$ & 2.36 & 580 & [86] \\
\hline $\mathrm{Cs}_{3} \mathrm{Sb}_{2} \mathrm{Br}_{9} \mathrm{NCs}$ & 2 & $P m 1$ & - & 410 & [87] \\
\hline $\mathrm{Rb}_{3} \mathrm{Sb}_{2} \mathrm{I}_{9}$ powder & 2 & $P 1 c 1$ & 1.98 & - & [85] \\
\hline $\mathrm{Rb}_{3} \mathrm{Sb}_{2} \mathrm{I}_{9} \mathrm{NCs}$ & 2 & $P 2_{1} / n$ & 1.95 & 630 & {$[88]$} \\
\hline $\mathrm{Cs}_{2} \mathrm{AgBiCl}_{6} \mathrm{SCs}$ & 3 & $P m 3 m$ & 2.77 & - & [53] \\
\hline $\mathrm{Cs}_{2} \mathrm{AgBiBr}_{6} \mathrm{SCs}$ & 3 & $P m 3 m$ & 2.07 & 685 & {$[54]$} \\
\hline $\mathrm{Cs}_{2} \mathrm{AgBiBr}_{6} \mathrm{NCs}$ & 3 & $P m 3 m$ & 1.97 & 650 & [57] \\
\hline $\mathrm{Cs}_{2} \mathrm{AgInCl}_{6} \mathrm{SCs}$ & 3 & $P m 3 m$ & 3.3 & 585 & {$[61]$} \\
\hline $\mathrm{Cs}_{2} \mathrm{AgInCl}_{6} \mathrm{SCs}$ & 3 & $P m 3 m$ & 3.23 & 635 & [40] \\
\hline $\mathrm{Cs}_{2} \mathrm{NaInCl}_{6} \mathrm{SCs}$ & 3 & $P m 3 m$ & 4.55 & - & {$[64]$} \\
\hline
\end{tabular}

structure of the anatase phase was more compatible with $\mathrm{MASnI}_{3}$ [126]. Gao et al. [127] prepared a $\mathrm{MASnI}_{3}$ film containing lead thiocyanate additives, which significantly improved the film morphology. The absorption edge of the film was located at $950 \mathrm{~nm}$, and the corresponding device exhibited a PCE of $6.03 \%$. The \{en\}FASnI hollow structure, with randomly distributed Schottky defects and significantly increased bandgap and stability, was produced by incorporating ethylenediamine (en) to $\mathrm{FASnI}_{3}$. The corresponding device achieved a PCE of 7.14\% [128]. A mixture of $\mathrm{FA}^{+}$and $\mathrm{MA}^{+}$cations also effectively improved film morphology and reduced carrier recombination. An $\quad \mathrm{FA}_{0.75} \mathrm{MA}_{0.25} \mathrm{SnCl}_{3}$-based device containing a $\mathrm{SnF}_{2}$ additive exhibited a PCE of $8.12 \%$ [129]. In 2018, Jokar et al. [130] reduced the number of tin vacancies in $\mathrm{FASnI}_{3}$ by introducing bromide, considerably increasing the open-circuit voltage $\left(V_{\mathrm{oc}}\right)$ and fill factor (FF) of the fabricated solar cell; a PCE of 5.5\% was reported. Ran et al. [131] produced $\mathrm{FASnI}_{3}$ thin films with significantly improved uniformity and surface coverage, obtaining optoelectronic devices with a PCE of 6.98\%. Liu et al. [132] reported a pretreatment method to fabricate a $\mathrm{FASnI}_{3}$ film by spin-coating a solution of $n$ propylammonium iodide (PAI) in a mixed chloroform/ DMSO solvent. DMSO dissolved the surface crystals, creating a liquid-phase environment, while the large PAI 

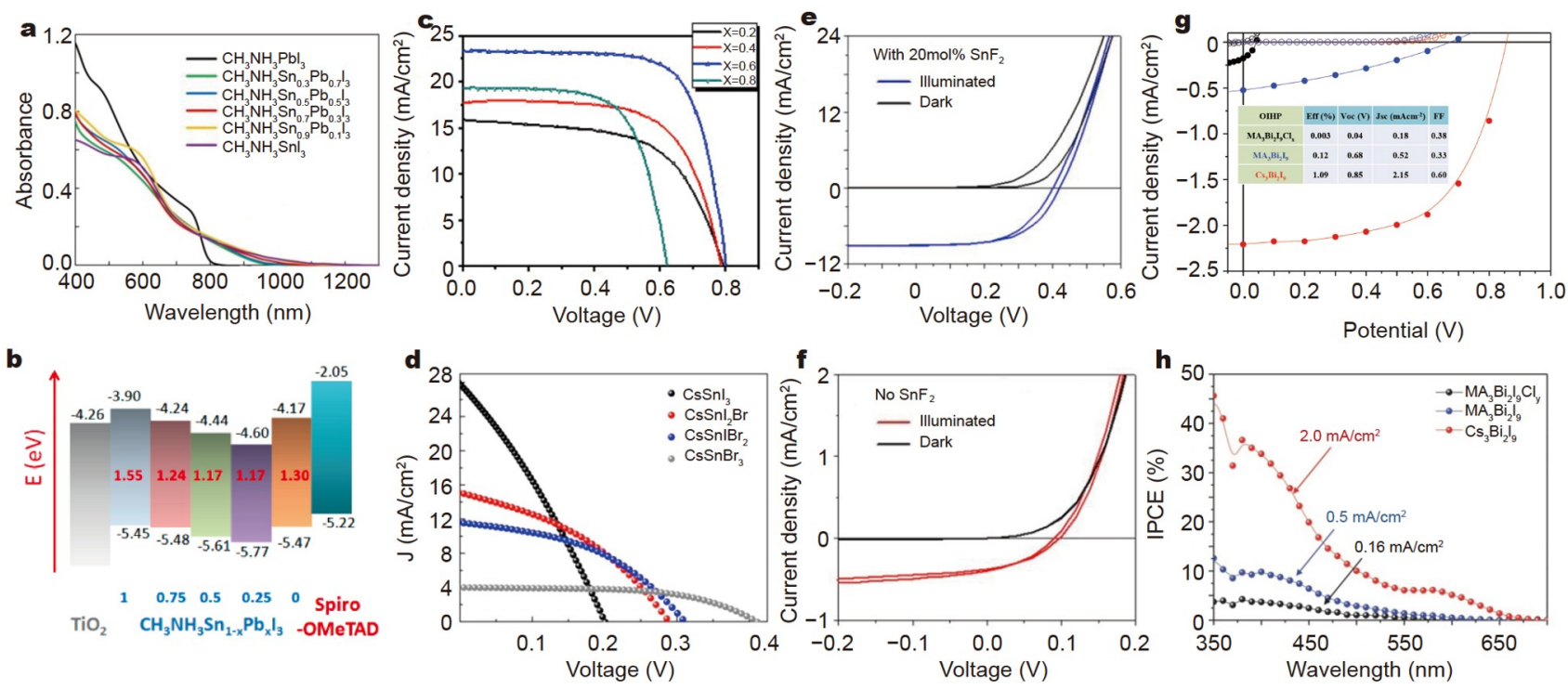

Figure 12 (a) Absorption spectra for $\mathrm{MASn}_{x} \mathrm{~Pb}_{1-x} \mathrm{I}_{3}$. Reprinted with permission from Ref. [119]. Copyright 2014, the American Chemical Society. (b) Schematic energy level diagram for $\mathrm{MASn}_{x} \mathrm{~Pb}_{1-x} \mathrm{I}_{3}$ solid-solution perovskites. Reprinted with permission from Ref. [120]. Copyright 2014, the American Chemical Society. (c) $J-V$ curves for MAPb ${ }_{1-x} \mathrm{Sn}_{x} \mathrm{I}_{2.6} \mathrm{Br}_{0.4}$ PSCs. Reprinted with permission from Ref. [122]. Copyright 2018, Elsevier. (d) $J-V$ curves for $\mathrm{CsSnI}_{3-x} \mathrm{Br}_{x}(0 \leq x \leq 3)$ PSCs. Reprinted with permission from Ref. [133]. Copyright 2015, the American Chemical Society. (e) $J-V$ curves for $\mathrm{CsSnBr}_{3}$ PSCs containing a $\mathrm{SnF}_{2}$ additive. (f) $J-V$ curves for $\mathrm{CsSnBr}_{3}$ PSCs with no $\mathrm{SnF}_{2}$. (e) and (f) are reprinted with permission from Ref. [134]. Copyright 2016, the American Chemical Society. (g) $J-V$ curves for $\mathrm{MA}_{3} \mathrm{Bi}_{2} \mathrm{I}_{9} \mathrm{Cl}_{\mathrm{x}}, \mathrm{MA}_{3} \mathrm{Bi}_{2} \mathrm{I}_{9}$, and $\mathrm{Cs}_{3} \mathrm{Bi}_{2} \mathrm{I}_{9}$ solar cells. (h) Incidental photon-to-electron conversion efficiency (IPCE) curves for $\mathrm{MA}_{3} \mathrm{Bi}_{2} \mathrm{I}_{9} \mathrm{Cl}_{x}, \mathrm{MA}_{3} \mathrm{Bi}_{2} \mathrm{I}_{9}$, and $\mathrm{Cs}_{3} \mathrm{Bi}_{2} \mathrm{I}_{9}$ solar cells. (g) and (h) are reprinted with permission from Ref. [99]. Copyright 2015, Wiley.

cations surrounded the $\mathrm{FASnI}_{3}$ nuclei to form a template. Therefore, a highly crystallized and smooth $\mathrm{FASnI}_{3}$ film with a low defect density was formed. The corresponding device exhibited a stabilized efficiency of $11.22 \%$, among the highest reported for lead-free PSCs.

Sabba et al. [133] successfully improved the $V_{\mathrm{oc}}$ and $J_{\mathrm{sc}}$ values of the corresponding device by adjusting the ratios of $\mathrm{I}$ and $\mathrm{Br}$ in $\mathrm{CsSnI}_{3-x} \mathrm{Br}_{x}$. As the $\mathrm{Br}$ content increased, the number of $\mathrm{Sn}$ vacancies gradually decreased, and the device output voltage gradually increased (Fig. 12d). Using $\mathrm{SnF}_{2}$ additive reduced the $\mathrm{Sn}$ vacancy concentration in $\mathrm{CsSnI}_{3}$, with the corresponding device exhibiting a PCE of $2 \%$ and significantly improved stability (Fig. 12e and f) [134]. Lee et al. [135] obtained a PCE of 2.1\% for $\mathrm{Cs}_{2} \mathrm{SnI}_{4} \mathrm{Br}_{2}$ perovskite devices prepared using a two-step method. Zhu et al. [136] controlled the relative content of $\mathrm{I}^{-} / \mathrm{Cl}^{-}$in $\mathrm{Cs}_{2} \mathrm{SnI}_{x} \mathrm{Cl}_{6-x}$, such that the band gap was easily adjusted. The efficiency of planar $\mathrm{Cs}_{2} \mathrm{SnI}_{6}$ PSCs prepared by Qiu et al. [137] was close to 1\%, and they demonstrated excellent stability after one week. The efficiency of $\mathrm{Cs}_{2} \mathrm{SnI}_{6}$-based PSCs employing pulsed laser-deposited $\mathrm{ZnO}$ nanorods as the electron transport material was close to $1 \%$. The nanorods adsorbed a larger amount of $\mathrm{Cs}_{2} \mathrm{SnI}_{6}$, improving the morphology of the film and in- hibiting charge recombination [138]. A $\mathrm{Cs}_{2} \mathrm{SnI}_{6}$ film with a pure crystal phase was prepared using aerosol-assisted CVD (AACVD). The film presented a bandgap of $1.3 \mathrm{eV}$ and a uniform morphology. In this process, $\mathrm{SnI}_{4}$ vapor prevented the decomposition of $\mathrm{Cs}_{2} \mathrm{SnI}_{6}$, thereby improving the film stability [139].

\section{Double perovskite solar cells}

In 2017, Wu et al. [140] prepared stable $\mathrm{Cs}_{2} \mathrm{AgBiBr}_{6}$ thin films through spin-coating and low-pressure-assisted annealing. A planar heterojunction solar cell based on this thin film showed a PCE of $1.44 \%$. Ning et al. [141] determined that excitons and free carriers in $\mathrm{Cs}_{2} \mathrm{AgBiBr}_{6}$ possessed a diffusion length of $110 \mathrm{~nm}$. Gao et al. [142] added isopropanol during the spin-coating of $\mathrm{Cs}_{2} \mathrm{AgBiBr}_{6}$ thin films and combined this with high-temperature annealing to prepare thin films with smooth surfaces and large grain sizes. Solar cells based on an inverted planar heterojunction showed a PCE of 2.23\%. Igbari et al. [143] compared $\mathrm{Cs}_{2} \mathrm{AgBiBr}_{6}$ films prepared by either vacuum sublimation or solution methods. The authors observed that the solution-treated films exhibited higher crystallinity, narrower electronic bandgap, longer light excitation lifetimes, and higher mobility. The resulting solar cell 
presented an optimized PCE of $2.51 \%$. Various other techniques, such as high-pressure evaporation deposition [144] and metal doping, have been utilized to improve thin-film crystallization quality. When $\mathrm{Rb}^{+}$was doped in $\mathrm{Cs}_{2} \mathrm{AgBiBr}_{6}$ to form $\left(\mathrm{Cs}_{1-x} \mathrm{Rb}_{x}\right)_{2} \mathrm{AgBiBr}_{6}$, light absorption in the long-wavelength region was enhanced, and the defect state density was reduced without changing the crystal lattice. When Cs:Rb = 9:1, the average PCE of the device was 15 times higher than that of the undoped device [145]. Changing the device structure can also improve the efficiency. Pantaler et al. [146] deposited a $\mathrm{Cs}_{2} \mathrm{AgBiBr}_{6}$ film on mesoporous $\mathrm{TiO}_{2}$, allowing the uniform and compact growth of the perovskite and increasing its contact area with $\mathrm{TiO}_{2}$.

Although extensive research has been performed on the $\mathrm{Cs}_{2} \mathrm{AgBiBr}_{6}$ double perovskite, the performance of $\mathrm{Cs}_{2} \mathrm{AgBiBr}_{6}$ PSCs is substantially inferior to that of devices using lead-based perovskites. Studies have shown that the electron diffusion length in $\mathrm{Cs}_{2} \mathrm{AgBiBr}_{6}$ is shorter than the hole diffusion length. The high electron trap density was the major reason for these carrier diffusion lengths [147]. These challenges must be overcome in future studies.

\section{$B i$, Sb(III)-based perovskite solar cells}

Park et al. [99] successfully fabricated zero-dimensional $\mathrm{A}_{3} \mathrm{Bi}_{2} \mathrm{I}_{9}(\mathrm{~A}=\mathrm{MA}$ or $\mathrm{Cs})$ perovskites and integrated them in photovoltaic devices. The bandgaps of $\mathrm{MA}_{3} \mathrm{Bi}_{2} \mathrm{I}_{9}$, $\mathrm{Cs}_{3} \mathrm{Bi}_{2} \mathrm{I}_{9}$, and $\mathrm{MA}_{3} \mathrm{Bi}_{2} \mathrm{I}_{9-x} \mathrm{Cl}_{x}$ were approximately 2.1, 2.2, and $2.4 \mathrm{eV}$, respectively. $\mathrm{Cs}_{3} \mathrm{Bi}_{2} \mathrm{I}_{9}$-based solar cells exhibited PCEs exceeding 1\% (Fig. 12g and h). Shin et al.
[148] developed a solvent engineering method to prepare dense $\mathrm{A}_{3} \mathrm{Bi}_{2} \mathrm{I}_{9}\left(\mathrm{~A}=\mathrm{MA}^{+}, \mathrm{Cs}^{+}\right.$, or $\left.\mathrm{FA}^{+}\right)$thin films. $\mathrm{MA}_{3} \mathrm{Bi}_{2} \mathrm{I}_{9}$-based devices presented the highest PCE of $0.71 \%$. Jain et al. [149] exposed a $\mathrm{BiI}_{3}$ film to MAI steam by a steam-assisted solution process. The best reported PCE of the highly stable $\mathrm{MA}_{3} \mathrm{Bi}_{2} \mathrm{I}_{9}$-based devices was $3.17 \%$. Saparov et al. [81] prepared a $\mathrm{Cs}_{3} \mathrm{Sb}_{2} \mathrm{I}_{9}$ film using a two-step deposition method. This film exhibited a bandgap width of only $2.05 \mathrm{eV}$. Comparison of the stabilities of $\mathrm{Cs}_{3} \mathrm{Sb}_{2} \mathrm{I}_{9}$ and $\mathrm{MAPbI}_{3}$ under identical conditions revealed that $\mathrm{Cs}_{3} \mathrm{Sb}_{2} \mathrm{I}_{9}$ decomposed and produced small amounts of CsI over 60 days, while $\mathrm{MAPbI}_{3}$ decomposed drastically in two weeks. The various performance parameters of lead-free PSCs are listed in Table 2.

\section{LEDs}

Materials used in light-emitting and photovoltaic devices require different design principles. Light-emitting devices must have effective exciton recombination through radiation pathways, while the effective separation of excitons is essential for effective photoelectric conversion in solar cell devices. Therefore, luminescent metal halide perovskites exhibiting quantum confinement are suitable for use in light-emitting devices. Owing to the higher probability of exciton recombination in a confined structure, large exciton binding energies can be obtained. Hence, nano-sized perovskites can show higher PLQYs than expected. Two different optical processes are used as guidelines to manufacture efficient light-emitting devices based on emissive materials [150]. One process is PL; PLbased devices employ a separate high-energy light source

Table 2 Parameters of lead-free PSCs

\begin{tabular}{|c|c|c|c|c|c|}
\hline & $J_{\mathrm{sc}}\left(\mathrm{mA} \mathrm{cm}^{-2}\right)$ & $V_{\mathrm{oc}}(\mathrm{V})$ & $\mathrm{FF}$ & PCE (\%) & Ref. \\
\hline $\mathrm{MASn}_{0.5} \mathrm{~Pb}_{0.5} \mathrm{I}_{3}$ & 20.04 & 0.42 & 0.5 & 4.18 & [119] \\
\hline $\mathrm{MAPb}_{0.4} \mathrm{Sn}_{0.6} \mathrm{I}_{2.6} \mathrm{Br}_{0.4}$ & 23.38 & 0.80 & 0.72 & 13.40 & [122] \\
\hline $\mathrm{MASnI}_{3}$ & 15.18 & 0.72 & 0.50 & 5.44 & [124] \\
\hline $\mathrm{MASnI}_{3}$ & 17.03 & 0.54 & 0.66 & 6.03 & [127] \\
\hline$\{$ en $\} \mathrm{FASnI}_{3}$ & 22.54 & 0.48 & 0.66 & 7.14 & [128] \\
\hline $\mathrm{FA}_{0.75} \mathrm{MA}_{0.25} \mathrm{SnI}_{3}$ & 21.2 & 0.61 & 0.63 & 8.12 & [129] \\
\hline $\mathrm{FASnI}_{3}$ & 20.7 & 0.47 & 0.74 & 6.98 & [131] \\
\hline $\mathrm{CsSnI}_{2} \mathrm{Br}$ & 15.6 & 0.29 & 0.38 & 1.67 & [133] \\
\hline $\mathrm{Cs}_{2} \mathrm{SnI}_{4} \mathrm{Br}_{2}$ & 6.22 & 0.56 & 0.57 & 2.03 & [135] \\
\hline $\mathrm{Cs}_{2} \mathrm{SnI}_{6}$ & 5.41 & 0.51 & 0.35 & 0.96 & [137] \\
\hline $\mathrm{FASnI}_{3}$ & 22.10 & 0.72 & 0.73 & 11.2 & [132] \\
\hline $\mathrm{MA}_{3} \mathrm{Bi}_{2} \mathrm{I}_{9}$ & 4.2 & 1.01 & 0.78 & 3.17 & [149] \\
\hline $\mathrm{Cs}_{3} \mathrm{Bi}_{2} \mathrm{I}_{9}$ & 2.15 & 0.85 & 0.6 & 1.09 & [99] \\
\hline $\mathrm{Cs}_{2} \mathrm{AgBiBr}_{6}$ & 3.82 & 1.01 & 0.65 & 2.51 & [143] \\
\hline
\end{tabular}




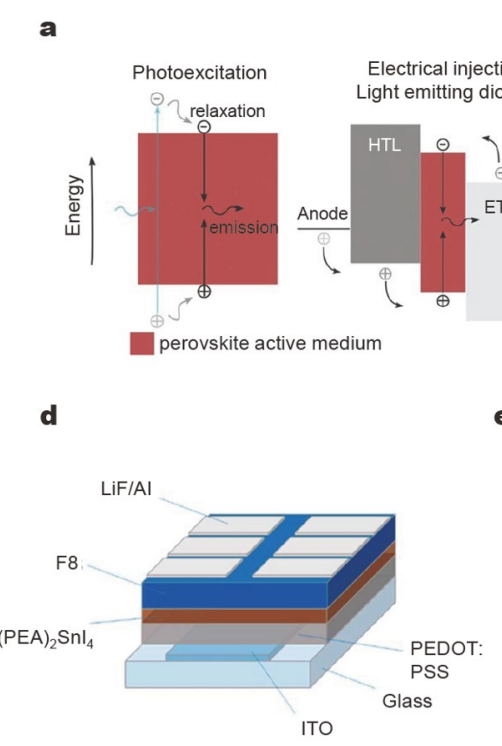

b

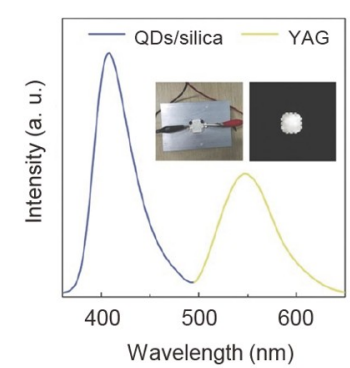

c

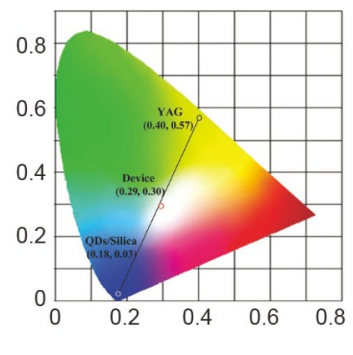

e

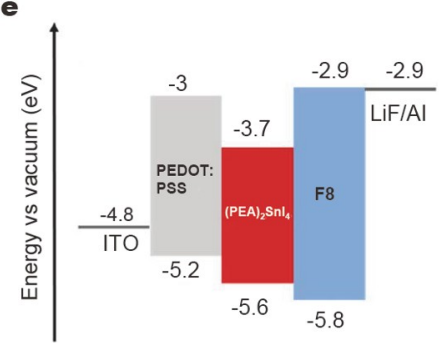

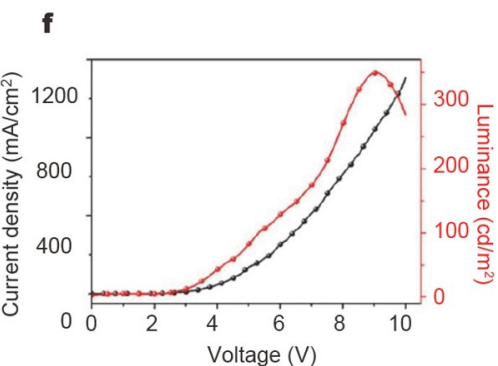

Figure 13 (a) Photo and electrical excitation of perovskite materials. Reprinted with permission from Ref. [150]. Copyright 2018, Wiley. (b) EL spectrum for a white LED (w-LED) combing $\mathrm{Cs}_{3} \mathrm{Bi}_{2} \mathrm{Br}_{9}$ QDs and the rare-earth phosphor YAG. Insets: digital images of QDs/silica composite devices combined with YAG (off and on). (c) Commission internationale de l'eclairage (CIE) color coordinates for $\mathrm{Cs}_{3} \mathrm{Bi}_{2} \mathrm{Br}_{9}$ QDs, YAG, and the W-LED device. (b) and (c) are reprinted with permission from Ref. [75]. Copyright 2018, Wiley. (d) Device structure of the (PEA) ${ }_{2}$ SnI $_{4}$ perovskite LEDs. (e) Energy levels for a (PEA) $\mathrm{SnI}_{4}$ perovskite LEDs. (d) and (e) are reprinted with permission from Ref. [93]. Copyright 2017, the American Chemical Society. (f) Current density (black) and brightness (red) as a function of the voltage for a $(\mathrm{OAm})_{2} \mathrm{SnBr}_{4}$ perovskite LED. Reprinted with permission from Ref. [94]. Copyright 2018, the American Chemical Society.

for photoexcitation, with energy corresponding to the optical bandgap of the emissive material. The second process is electroluminescence (EL); electrons and holes are injected from the cathode and anode, respectively, into the functional layer under an external electric field, and energy is released from the active layer as luminescence (Fig. 13a). Tang's group [75] prepared $\mathrm{Cs}_{3} \mathrm{Bi}_{2} \mathrm{X}_{9}$ NCs with a PL peak at $410 \mathrm{~nm}(\mathrm{FWHM}=48 \mathrm{~nm})$ and a PLQY of $19.4 \%$. The crystal surface was passivated by a $\mathrm{BiOBr}$ layer, providing superior water stability. The NCs were mixed with the yellow-emitting rare-earth phosphor $\mathrm{Y}_{3} \mathrm{Al}_{5} \mathrm{O}_{12}$ (YAG) and coated on an ultraviolet GaN chip. The combination of emission peaks from the $\mathrm{Cs}_{3} \mathrm{Bi}_{2} \mathrm{X}_{9}$ NCs and YAG produced white emission with good light and thermal stabilities. The color temperature was determined to be $8477.1 \mathrm{~K}$ (Fig. 13b and c). Zhang's group [151] prepared $\mathrm{CsPb}_{x} \mathrm{Mn}_{1-x} \mathrm{Cl}_{3} \mathrm{NCs}$ using $\mathrm{Mn}^{2+}$ doping to reduce the toxic $\mathrm{Pb}^{2+}$ content. The value of $x$ reached 0.46 and the PL peak of the final product was located at $579 \mathrm{~nm}$, with a PLQY of $54 \%$. By coating the orange-redemitting $\mathrm{CsPb}_{0.73} \mathrm{Mn}_{0.27} \mathrm{Cl}_{3}$ NCs on a GaN LED chip, luminescence from the bottom GaN layer was converted into low-energy luminescence emitted from the perovskite NCs. Stable operation of the device was realized and a luminous efficiency of $2.21 \mathrm{~mW}^{-1}$ was achieved. Ma's group [152] synthesized zero-dimensional, organic, and lead-free $\left(\mathrm{C}_{4} \mathrm{~N}_{2} \mathrm{H}_{14} \mathrm{X}\right)_{4} \mathrm{SnX}_{6} \quad(\mathrm{X}=\mathrm{Br}, \mathrm{I})$ and $\left(\mathrm{C}_{9} \mathrm{NH}_{20}\right)_{2} \mathrm{SbCl}_{5}$ perovskites, in which the metal halide octahedral $\left[\mathrm{SnX}_{6}\right]$ and tetrahedral $\left[\mathrm{SbX}_{5}\right]$ units were separated by the organic ligands $\mathrm{C}_{4} \mathrm{~N}_{2} \mathrm{H}_{14} \mathrm{X}^{+}$and $\mathrm{C}_{9} \mathrm{NH}_{20}{ }^{+}$. Efficient emission was realized by excited-state recombination in each metal halide polyhedron. A PLQY close to $100 \%$ was achieved, and the prepared white phosphor LEDs retained stable brightness and color after continuous operation for $6 \mathrm{~h}$.

The EL process is more efficient than the PL process in light-emitting devices. Haque's group [93] used the twodimensional (PEA) ${ }_{2} \mathrm{SnI}_{4}$ perovskite as a $\mathrm{TiO}_{2}$ sensitizer to prepare an LED with the structure ITO/PEDOT:PSS/ (PEA) $)_{2} \mathrm{SnI}_{4} / \mathrm{F} 8 / \mathrm{LiF} / \mathrm{Al}$. This device exhibited an EL peak at $630 \mathrm{~nm}$ under the current density of $4.7 \mathrm{~mA} \mathrm{~cm}^{-2}$ and achieved a brightness of $0.15 \mathrm{CD} \mathrm{m}^{-2}$ (Fig. 13d and e). Tan's group [153] prepared an LED device with the structure ITO/PEDOT:PSS/MASnI 3 /F8/Ca/Ag, displaying near-infrared EL at $945 \mathrm{~nm}$ and an external quantum efficiency of $0.72 \%$. With increasing $\mathrm{Br}$ content in $\operatorname{MASn}\left(\mathrm{Br}_{1-x} \mathrm{I}_{x}\right)_{3}$, the bandgap increased and the EL of the corresponding LED device was blue-shifted from 945 to 
$667 \mathrm{~nm}$. Zhang et al. [94] synthesized two-dimensional $(\mathrm{OAm})_{2} \mathrm{SnBr}_{4}$ perovskite NCs by hot injection. The PLQY values were $88 \%$ and $68 \%$ for the NCs in solution and film states, respectively, owing to the effective separation of $\left[\mathrm{SnBr}_{6}\right]$ octahedra by the $\mathrm{OAm}^{+}$insulation layer. $(\mathrm{OAm})_{2} \mathrm{SnBr}_{4}$ was used as the light-emitting layer in an inverted LED, exhibiting a low conduction voltage of $2.2 \mathrm{~V}$ and a maximum brightness of $350 \mathrm{CD} \mathrm{m} \mathrm{m}^{-2}$, the highest brightness reported to date for lead-free perovskite LEDs (Fig. 13f). Yuan et al. [154] used valeric acid (VA) to decrease the crystallization rate of a $(\mathrm{PEA})_{2} \mathrm{SnI}_{4}$ perovskite, improving the film morphology. The addition of VA also protected tin from oxidation during film formation. The high-quality film and the reduced $\mathrm{Sn}^{4+}$ content contributed to the high external quantum efficiency (5\%) of the resulting LEDs. The color coordinates of the LEDs were $(0.708,0.292)$, meeting the Rec. 2100 specification for a red emitter.

\section{$\mathrm{X}$-ray detectors}

The absorption of X-ray and the effective conversion of photons to carriers are vital for the application of X-ray detectors. High X-ray sensitivities, large charge-carrier mobilities, long charge-carrier lifetimes $(\tau)$, and low defect densities are required for scintillators. Zhang et al. [155] fabricated an X-ray detector based on $\mathrm{Cs}_{2} \mathrm{AgBiBr}_{6}$. In the preparation of single-crystal $\mathrm{Cs}_{2} \mathrm{AgBiBr}_{6}$, washing with isopropanol during high-temperature annealing inhibited the field-driven ion migration and the formation of surface conduction channels, thereby reducing the resistivity and background current of the device. The sensitivity of the X-ray detector was $316 \mu \mathrm{C} \mathrm{Gy}_{\text {air }}{ }^{-1} \mathrm{~cm}^{-2}$ at a voltage of $18 \mathrm{~V}$. Three-dimensional single-crystal perovskites exhibit high mobilities and long carrier diffusion lengths, producing high dark currents when they are used in optoelectronic devices. Moreover, internal ions can migrate easily, particularly under high electric fields, causing detector instability under working conditions, low device signal-to-noise ratios, and baseline drift [156-158]. The crystal grain defect concentration of perovskite structures can be effectively suppressed by reducing the size $[159,160]$. Xu et al. [161] reported that the layered double perovskite $(\mathrm{BA})_{2} \mathrm{CsAgBiBr}_{7}\left(\mathrm{BA}^{+}=n\right.$ butylammonium) exhibited a low number of defects and high resistivity. This perovskite presented excellent X-ray attenuation characteristics, based on its X-ray detector sensitivity of $4.2 \mu \mathrm{C} \mathrm{Gy}_{\text {air }}{ }^{-1} \mathrm{~cm}^{-2}$, indicating its excellent potential as an X-ray detector material. Liu et al. [162] synthesized large-volume, zero-dimensional inorganic single-crystal $\mathrm{MA}_{3} \mathrm{Bi}_{2} \mathrm{I}_{9}$ with a high $\mathrm{X}$-ray absorption $\left(\sim 4.1 \mathrm{~g} \mathrm{~cm}^{-3}\right)$, and a resistivity of $4.7 \times 10^{10} \Omega \mathrm{cm}$. A coplanar detector fabricated using $\mathrm{MA}_{3} \mathrm{Bi}_{2} \mathrm{I}_{9}$ SCs exhibited low dark noise current and excellent $\mathrm{X}$-ray response performance, with a minimum detection limit of $31 \mathrm{nGy} \mathrm{s}^{-1}$ and a high sensitivity of $872 \mu \mathrm{C} \mathrm{Gy}^{-1} \mathrm{~cm}^{2}$. Tie et al. [163] reported that polycrystalline $\mathrm{MA}_{3} \mathrm{Bi}_{2} \mathrm{I}_{9}$ presented a high resistivity and a low dark carrier concentration. The low limit of detection (LoD) of the $\mathrm{MA}_{3} \mathrm{Bi}_{2} \mathrm{I}_{9}$-polycrystalline pellet detector was $9.3 \mathrm{nGy}_{\text {air }} \mathrm{s}^{-1}$, with a detection efficiency (28.8\%) higher than that of $\mathrm{MAPbBr}_{3}$ SCs (16.4\%) (Fig. 14a). The inorganic zerodimensional bismuth perovskite is also an ideal material for X-ray detectors. Centimeter-sized $\mathrm{Cs}_{3} \mathrm{Bi}_{2} \mathrm{I}_{9}$ SCs [101] exhibited low defect density, low trap density, extremely low dark-current noise, and high stability. The fabricated single-crystal $\mathrm{Cs}_{3} \mathrm{Bi}_{2} \mathrm{I}_{9}$ perovskite X-ray detector showed a high light response with an on/off ratio exceeding $10^{3}$ and a high detection rate $\left(10^{12}\right.$ Jones). Low-temperaturegrown $\left(\mathrm{NH}_{4}\right)_{3} \mathrm{Bi}_{2} \mathrm{I}_{9} \mathrm{SCs}$ could be sheared along the cleavage plane. An obvious anisotropic $\mathrm{X}$-ray response was observed in $\left(\mathrm{NH}_{4}\right)_{3} \mathrm{Bi}_{2} \mathrm{I}_{9}$ owing to parallel charge transport and collection anisotropy. The perpendicularly structured device exhibited a greater sensitivity than the parallelly structured device (Fig. 14b and c) [73].
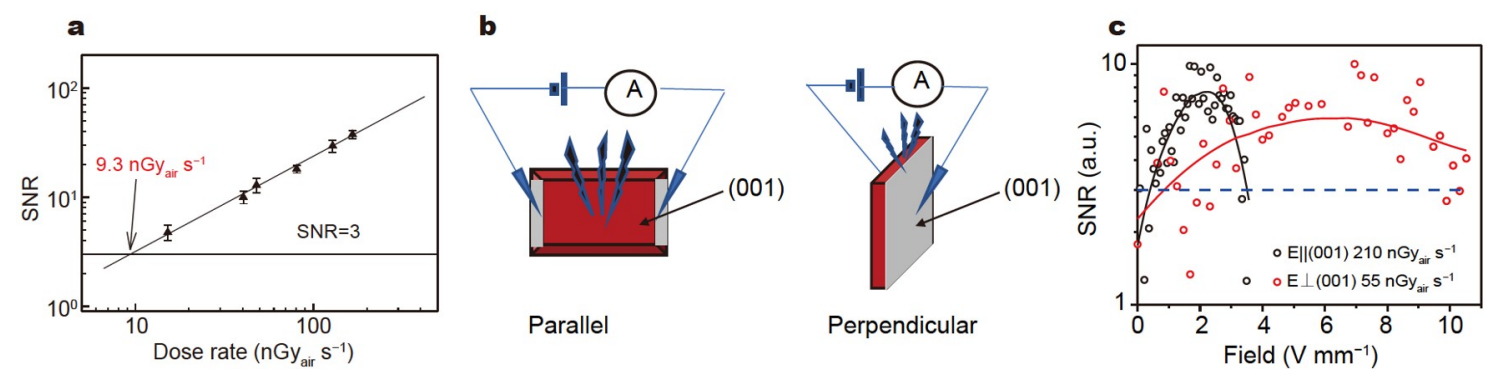

Figure 14 (a) X-ray dose-rate-dependent signal-to-noise ratio (SNR) of a detection device under an electric field of $700 \mathrm{~V} \mathrm{~cm}{ }^{-1}$. Reprinted with permission from Ref. [163]. Copyright 2020, Wiley. (b) Illustration of parallel and perpendicular device structures. (c) Sensitivities of devices parallel and perpendicular to the (001) surface. (b) and (c) are reprinted with permission from Ref. [73]. Copyright 2019, Springer Nature. 


\section{CONCLUSIONS AND OUTLOOK}

In recent years, great progress has been made in the development of suitable lead-free alternative perovskites to address the toxicity of lead. Three aspects of Sn-, Bi-, Sbbased, and double perovskites were discussed in this review: growth methods, photoelectric properties, and device applications. The growth methods for lead-free perovskites were similar to those employed for lead-based perovskites. Various forms of lead-free perovskites can be synthesized using solution methods, solid-state reactions, and CVD. Each growth method has its advantages and disadvantages, and a suitable method should be selected according to the material requirements. For example, the anti-solvent method allows the synthesis of high-quality single-crystal Bi-based perovskites; however, the size of the synthesized QDs is uneven and the QDs are easily aggregated. The hot injection method is a more suitable choice to synthesize uniformly sized QDs.

The atomic radius and the arrangement of electron orbitals significantly influence the selection of alternative perovskite elements. The different valence states of an element and the different structures of a single valence state are also important factors governing the photoelectric properties of the material. For example, Sn(II)and $\mathrm{Sn}(\mathrm{IV})$-based perovskites present two different structures; therefore, the electronic structure and optical properties of the perovskites differ. The bandgaps of $\mathrm{Sn}(\mathrm{II})$-based perovskites are generally smaller than those of $\mathrm{Sn}(\mathrm{IV})$-based perovskites, and Sn(IV)-based perovskites are more stable than $\mathrm{Sn}$ (II)-based perovskites. $\mathrm{A}_{3}(\mathrm{Bi} / \mathrm{Sb})_{2} \mathrm{X}_{9}$ exhibits two different structures when different $\mathrm{A}$ cations and halogen atoms are incorporated, producing distinct energy band structures and carrier dynamics.

We also examined the properties of two reported double perovskites: $\mathrm{Cs}_{2} \mathrm{AgBiX}_{6}$ and $\mathrm{Cs}_{2} \mathrm{AgInX}_{6}$. Using these as examples, we discussed the methods to optimize the properties of lead-free perovskites, such as halogen substitution, metal element doping, energy band engineering, and adjusting the structure dimensions.

Finally, the applications of lead-free perovskites in solar cells, LEDs, and X-ray detectors were reviewed. To date, the conversion efficiency of $\mathrm{Sn}$ (II)-based perovskite photoelectric devices is above $10 \%$, lagging behind that of lead-based perovskites. The major reason for this is that $\mathrm{Sn}(\mathrm{II})$ can be easily oxidized to Sn(IV), causing p-type doping. For LEDs and X-ray detectors, the efficient separation of excitons and the X-ray sensitivity of lead-free perovskites are important research directions.

In future, research on lead-free perovskite will be challenging; researchers can focus on the physical and chemical optimization of these materials to approach the excellent properties of lead-based perovskites. It is also important to study the unique properties of lead-free perovskites that are different from those of lead-based perovskites, and to expand their application scope.

Received 8 February 2021; accepted 7 July 2021;

published online 27 August 2021

1 Poglitsch A, Weber D. Dynamic disorder in methylammoniumtrihalogenoplumbates(II) observed by millimeter-wave spectroscopy. J Chem Phys, 1987, 87: 6373-6378

2 Onoda-Yamamuro N, Matsuo T, Suga H. Dielectric study of $\mathrm{CH}_{3} \mathrm{NH}_{3} \mathrm{PbX}_{3}(\mathrm{X}=\mathrm{Cl}, \mathrm{Br}$, I). J Phys Chem Solids, 1992, 53: 935 939

3 Papavassiliou GC, Koutselas IB. Structural, optical and related properties of some natural three- and lower-dimensional semiconductor systems. Synth Met, 1995, 71: 1713-1714

4 Green MA, Ho-Baillie A, Snaith HJ. The emergence of perovskite solar cells. Nat Photon, 2014, 8: 506-514

5 Miyata A, Mitioglu A, Plochocka P, et al. Direct measurement of the exciton binding energy and effective masses for charge carriers in organic-inorganic tri-halide perovskites. Nat Phys, 2015, 11: 582-587

6 Ball JM, Lee MM, Hey A, et al. Low-temperature processed mesosuperstructured to thin-film perovskite solar cells. Energy Environ Sci, 2013, 6: 1739-1743

7 Liu D, Kelly TL. Perovskite solar cells with a planar heterojunction structure prepared using room-temperature solution processing techniques. Nat Photon, 2014, 8: 133-138

8 Nie W, Tsai H, Asadpour R, et al. High-efficiency solutionprocessed perovskite solar cells with millimeter-scale grains. Science, 2015, 347: 522-525

9 Kim HS, Lee CR, Im JH, et al. Lead iodide perovskite sensitized all-solid-state submicron thin film mesoscopic solar cell with efficiency exceeding 9\%. Sci Rep, 2012, 2: 591

10 Liu M, Johnston MB, Snaith HJ. Efficient planar heterojunction perovskite solar cells by vapour deposition. Nature, 2013, 501: 395398

11 Saliba M, Matsui T, Domanski K, et al. Incorporation of rubidium cations into perovskite solar cells improves photovoltaic performance. Science, 2016, 354: 206-209

$12 \mathrm{He} \mathrm{M,} \mathrm{Li} \mathrm{B,} \mathrm{Cui} \mathrm{X,} \mathrm{et} \mathrm{al.} \mathrm{Meniscus-assisted} \mathrm{solution} \mathrm{printing} \mathrm{of}$ large-grained perovskite films for high-efficiency solar cells. Nat Commun, 2017, 8: 16045

13 He M, Pang X, Liu X, et al. Monodisperse dual-functional upconversion nanoparticles enabled near-infrared organolead halide perovskite solar cells. Angew Chem, 2016, 128: 4352-4356

14 He M, Zheng D, Wang M, et al. High efficiency perovskite solar cells: From complex nanostructure to planar heterojunction. J Mater Chem A, 2014, 2: 5994-6003

15 Meng X, Cui X, Rager M, et al. Cascade charge transfer enabled by incorporating edge-enriched graphene nanoribbons for mesostructured perovskite solar cells with enhanced performance. Nano Energy, 2018, 52: 123-133

16 Sahli F, Werner J, Kamino BA, et al. Fully textured monolithic perovskite/silicon tandem solar cells with $25.2 \%$ power conversion efficiency. Nat Mater, 2018, 17: 820-826 
17 Ju MG, Chen M, Zhou Y, et al. Toward eco-friendly and stable perovskite materials for photovoltaics. Joule, 2018, 2: 1231-1241

18 Liu R, Zhou H, Wang R, et al. Space-confined growth of highquality $\mathrm{CsBi}_{3} \mathrm{I}_{10}$ lead-free perovskite film for near-infrared photodetectors with high sensitivity and stability. Sci China Mater, 2021, 64: 393-399

19 Li X, Du X, Zhang P, et al. Lead-free halide perovskite $\mathrm{Cs}_{3} \mathrm{Bi}_{2} \mathrm{Br}_{9}$ single crystals for high-performance X-ray detection. Sci China Mater, 2021, 64: 1427-1436

20 Wang Y, Yang D, Ma D, et al. Organic-inorganic hybrid Sn-based perovskite photodetectors with high external quantum efficiencies and wide spectral responses from 300 to $1000 \mathrm{~nm}$. Sci China Mater, 2019, 62: 790-796

21 Zhao D, Wang B, Liang C, et al. Facile deposition of high-quality $\mathrm{Cs}_{2} \mathrm{AgBiBr}_{6}$ films for efficient double perovskite solar cells. Sci China Mater, 2020, 63: 1518-1525

22 Yan G, Ji Z, Li Z, et al. All-inorganic $\mathrm{Cs}_{2} \mathrm{AgBiBr}_{6} / \mathrm{CuSCN}$-based photodetectors for weak light imaging. Sci China Mater, 2021, 64: 198-208

23 Dai Z, Tang W, Wang T, et al. Stable tin perovskite solar cells enabled by widening the time window for crystallization. Sci China Mater, 2021, 64: 1849-1857

24 Wang S, Yang F, Zhu J, et al. Growth of metal halide perovskite materials. Sci China Mater, 2020, 63: 1438-1463

25 Ju D, Jiang X, Xiao H, et al. Narrow band gap and high mobility of lead-free perovskite single crystal Sn-doped $\mathrm{MA}_{3} \mathrm{Sb}_{2} \mathrm{I}_{9}$. J Mater Chem A, 2018, 6: 20753-20759

26 Zhang $\mathrm{H}, \mathrm{Xu} \mathrm{Y}$, Sun Q, et al. Lead free halide perovskite $\mathrm{Cs}_{3} \mathrm{Bi}_{2} \mathrm{I}_{9}$ bulk crystals grown by a low temperature solution method. CrystEngComm, 2018, 20: 4935-4941

27 Liu Y, Yang Z, Liu SF. Recent progress in single-crystalline perovskite research including crystal preparation, property evaluation, and applications. Adv Sci, 2018, 5: 1700471

28 Ma S, Cai M, Cheng T, et al. Two-dimensional organic-inorganic hybrid perovskite: From material properties to device applications. Sci China Mater, 2018, 61: 1257-1277

29 Zuo C, Ding L. Lead-free perovskite materials $\left(\mathrm{NH}_{4}\right)_{3} \mathrm{Sb}_{2} \mathrm{I}_{x} \mathrm{Br}_{9-x}$. Angew Chem, 2017, 129: 6628-6632

30 Pascoe AR, Gu Q, Rothmann MU, et al. Directing nucleation and growth kinetics in solution-processed hybrid perovskite thin-films. Sci China Mater, 2017, 60: 617-628

31 Zhou Y, Game OS, Pang S, et al. Microstructures of organometal trihalide perovskites for solar cells: Their evolution from solutions and characterization. J Phys Chem Lett, 2015, 6: 4827-4839

32 Liu T, Dong X, Li J, et al. Effect of concomitant anti-solvent engineering on perovskite grain growth and its high efficiency solar cells. Sci China Mater, 2021, 64: 267-276

33 Hong WL, Huang YC, Chang CY, et al. Efficient low-temperature solution-processed lead-free perovskite infrared light-emitting diodes. Adv Mater, 2016, 28: 8029-8036

$34 \mathrm{Xi} \mathrm{J}, \mathrm{Wu} \mathrm{Z}$, Jiao B, et al. Multichannel interdiffusion driven $\mathrm{FASnI}_{3}$ film formation using aqueous hybrid salt/polymer solutions toward flexible lead-free perovskite solar cells. Adv Mater, 2017, 29: 1606964

35 Parobek D, Dong Y, Qiao T, et al. Direct hot-injection synthesis of Mn-doped CsPbBr 3 nanocrystals. Chem Mater, 2018, 30: 29392944

36 Grisorio R, Fanizza E, Striccoli M, et al. Shape tailoring of iodinebased cesium lead halide perovskite nanocrystals in hot-injection methods. ChemNanoMat, 2020, 6: 356-361
37 Zhang Y, Siegler TD, Thomas CJ, et al. A "tips and tricks" practical guide to the synthesis of metal halide perovskite nanocrystals. Chem Mater, 2020, 32: 5410-5423

38 Jellicoe TC, Richter JM, Glass HFJ, et al. Synthesis and optical properties of lead-free cesium tin halide perovskite nanocrystals. J Am Chem Soc, 2016, 138: 2941-2944

39 Liu Y, Jing Y, Zhao J, et al. Design optimization of lead-free perovskite $\mathrm{Cs}_{2} \mathrm{AgInCl}_{6}: \mathrm{Bi}$ nanocrystals with $11.4 \%$ photoluminescence quantum yield. Chem Mater, 2019, 31: 3333-3339

40 Zhou J, Xia Z, Molokeev MS, et al. Composition design, optical gap and stability investigations of lead-free halide double perovskite $\mathrm{Cs}_{2} \mathrm{AgInCl}_{6}$. J Mater Chem A, 2017, 5: 15031-15037

41 Zhou C, Tian Y, Wang M, et al. Low-dimensional organic tin bromide perovskites and their photoinduced structural transformation. Angew Chem Int Ed, 2017, 56: 9018-9022

42 Chung I, Song JH, Im J, et al. $\mathrm{CsSnI}_{3}$ : Semiconductor or metal? High electrical conductivity and strong near-infrared photoluminescence from a single material. High hole mobility and phase-transitions. J Am Chem Soc, 2012, 134: 8579-8587

43 Benin BM, Dirin DN, Morad V, et al. Highly emissive self-trapped excitons in fully inorganic zero-dimensional tin halides. Angew Chem Int Ed, 2018, 57: 11329-11333

44 Han M, Sun J, Peng M, et al. Controllable growth of lead-free allinorganic perovskite nanowire array with fast and stable near-infrared photodetection. J Phys Chem C, 2019, 123: 17566-17573

45 Waleed A, Tavakoli MM, Gu L, et al. Lead-free perovskite nanowire array photodetectors with drastically improved stability in nanoengineering templates. Nano Lett, 2017, 17: 523-530

46 Shen Y, Cheng LP, Li YQ, et al. High-efficiency perovskite lightemitting diodes with synergetic outcoupling enhancement. Adv Mater, 2019, 31: 1901517

47 Yin $\mathrm{H}$, Xian $\mathrm{Y}$, Zhang Y, et al. Structurally stabilizing and environment friendly triggers: Double-metallic lead-free perovskites. Sol RRL, 2019, 3: 1900148

48 Nedelcu G, Protesescu L, Yakunin S, et al. Fast anion-exchange in highly luminescent nanocrystals of cesium lead halide perovskites $\left(\mathrm{CsPbX}_{3}, \mathrm{X}=\mathrm{Cl}, \mathrm{Br}, \mathrm{I}\right)$. Nano Lett, 2015, 15: 5635-5640

49 Yuan F, Xi J, Dong H, et al. All-inorganic hetero-structured cesium tin halide perovskite light-emitting diodes with current density over $900 \mathrm{~A} \mathrm{~cm}^{-2}$ and its amplified spontaneous emission behaviors. Phys Status Solidi RRL, 2018, 12: 1800090

50 Kagan CR, Mitzi DB, Dimitrakopoulos CD. Organic-inorganic hybrid materials as semiconducting channels in thin-film fieldeffect transistors. Science, 1999, 286: 945-947

51 Stoumpos CC, Malliakas CD, Kanatzidis MG. Semiconducting tin and lead iodide perovskites with organic cations: Phase transitions, high mobilities, and near-infrared photoluminescent properties. Inorg Chem, 2013, 52: 9019-9038

52 Wu B, Zhou Y, Xing G, et al. Long minority-carrier diffusion length and low surface-recombination velocity in inorganic leadfree $\mathrm{CsSnI}_{3}$ perovskite crystal for solar cells. Adv Funct Mater, 2017, 27: 1604818

53 McClure ET, Ball MR, Windl W, et al. $\mathrm{Cs}_{2} \operatorname{AgBiX}_{6}(\mathrm{X}=\mathrm{Br}, \mathrm{Cl})$ : $\mathrm{New}$ visible light absorbing, lead-free halide perovskite semiconductors. Chem Mater, 2016, 28: 1348-1354

54 Slavney $\mathrm{AH}, \mathrm{Hu} \mathrm{T}$, Lindenberg $\mathrm{AM}$, et al. A bismuth-halide double perovskite with long carrier recombination lifetime for photovoltaic applications. J Am Chem Soc, 2016, 138: 2138-2141

55 Ning W, Zhao XG, Klarbring J, et al. Thermochromic lead-free halide double perovskites. Adv Funct Mater, 2019, 29: 1807375 
56 Li Q, Wang Y, Pan W, et al. High-pressure band-gap engineering in lead-free $\mathrm{Cs}_{2} \mathrm{AgBiBr}_{6}$ double perovskite. Angew Chem, 2017, 129: $16185-16189$

57 Bekenstein Y, Dahl JC, Huang J, et al. The making and breaking of lead-free double perovskite nanocrystals of cesium silver-bismuth halide compositions. Nano Lett, 2018, 18: 3502-3508

58 Yang B, Chen J, Yang S, et al. Lead-free silver-bismuth halide double perovskite nanocrystals. Angew Chem, 2018, 130: 54575461

59 Lamba RS, Basera P, Bhattacharya $\mathrm{S}$, et al. Band gap engineering in $\mathrm{Cs}_{2}\left(\mathrm{Na}_{x} \mathrm{Ag}_{1-x}\right) \mathrm{BiCl}_{6}$ double perovskite nanocrystals. J Phys Chem Lett, 2019, 10: 5173-5181

60 Chen N, Cai T, Li W, et al. Yb- and Mn-doped lead-free double perovskite $\mathrm{Cs}_{2} \mathrm{AgBiX}_{6}\left(\mathrm{X}=\mathrm{Cl}^{-}, \mathrm{Br}^{-}\right)$nanocrystals. ACS Appl Mater Interfaces, 2019, 11: 16855-16863

61 Volonakis G, Haghighirad AA, Milot RL, et al. $\mathrm{Cs}_{2} \mathrm{InAgCl}_{6}$ : A new lead-free halide double perovskite with direct band gap. J Phys Chem Lett, 2017, 8: 772-778

62 Luo J, Wang X, Li S, et al. Efficient and stable emission of warmwhite light from lead-free halide double perovskites. Nature, 2018, 563: $541-545$

63 Locardi F, Sartori E, Buha J, et al. Emissive Bi-doped double perovskite $\mathrm{Cs}_{2} \mathrm{Ag}_{1-x} \mathrm{Na}_{x} \mathrm{InCl}_{6}$ nanocrystals. ACS Energy Lett, 2019, 4: 1976-1982

64 Han P, Mao X, Yang S, et al. Lead-free sodium-indium double perovskite nanocrystals through doping silver cations for bright yellow emission. Angew Chem Int Ed, 2019, 58: 17231-17235

65 Tran TT, Panella JR, Chamorro JR, et al. Designing indirectdirect bandgap transitions in double perovskites. Mater Horiz, 2017, 4: 688-693

66 Yang B, Mao X, Hong F, et al. Lead-free direct band gap doubleperovskite nanocrystals with bright dual-color emission. J Am Chem Soc, 2018, 140: 17001-17006

67 Zhou J, Rong X, Zhang $\mathrm{P}$, et al. Manipulation of $\mathrm{Bi}^{3+} / \mathrm{In}^{3+}$ transmutation and $\mathrm{Mn}^{2+}$-doping effect on the structure and optical properties of double perovskite $\mathrm{Cs}_{2} \mathrm{NaBi}_{1-x} \mathrm{In}_{x} \mathrm{Cl}_{6}$. Adv Opt Mater, 2019, 7: 1801435

68 Lee W, Hong S, Kim S. Colloidal synthesis of lead-free silverindium double-perovskite $\mathrm{Cs}_{2} \mathrm{AgInCl}_{6}$ nanocrystals and their doping with lanthanide ions. J Phys Chem C, 2019, 123: 2665-2672

69 Lehner AJ, Fabini DH, Evans HA, et al. Crystal and electronic structures of complex bismuth iodides $A_{3} \mathrm{Bi}_{2} \mathrm{I}_{9}(A=\mathrm{K}, \mathrm{Rb}, \mathrm{Cs})$ related to perovskite: Aiding the rational design of photovoltaics. Chem Mater, 2015, 27: 7137-7148

70 Yu BB, Liao M, Yang J, et al. Alloy-induced phase transition and enhanced photovoltaic performance: the case of $\mathrm{Cs}_{3} \mathrm{Bi}_{2} \mathrm{I}_{9-x} \mathrm{Br}_{x}$ perovskite solar cells. J Mater Chem A, 2019, 7: 8818-8825

71 Morgan EE, Mao L, Teicher SML, et al. Tunable perovskitederived bismuth halides: $\mathrm{Cs}_{3} \mathrm{Bi}_{2}\left(\mathrm{Cl}_{1-x} \mathrm{I}_{x}\right)_{9}$. Inorg Chem, 2020, 59: 3387-3393

72 Sun S, Tominaka S, Lee JH, et al. Synthesis, crystal structure, and properties of a perovskite-related bismuth phase, $\left(\mathrm{NH}_{4}\right)_{3} \mathrm{Bi}_{2} \mathrm{I}_{9}$. APL Mater, 2016, 4: 031101

73 Zhuang R, Wang X, Ma W, et al. Highly sensitive X-ray detector made of layered perovskite-like $\left(\mathrm{NH}_{4}\right)_{3} \mathrm{Bi}_{2} \mathrm{I}_{9}$ single crystal with anisotropic response. Nat Photonics, 2019, 13: 602-608

74 Yang B, Chen J, Hong F, et al. Lead-free, air-stable all-inorganic cesium bismuth halide perovskite nanocrystals. Angew Chem, 2017, 129: 12645-12649

75 Leng M, Yang Y, Zeng K, et al. All-inorganic bismuth-based perovskite quantum dots with bright blue photoluminescence and excellent stability. Adv Funct Mater, 2018, 28: 1704446

76 Cao Y, Zhang Z, Li L, et al. An improved strategy for high-quality cesium bismuth bromine perovskite quantum dots with remarkable electrochemiluminescence activities. Anal Chem, 2019, 91: 8607-8614

77 Lian L, Zhai G, Cheng F, et al. Colloidal synthesis of lead-free allinorganic cesium bismuth bromide perovskite nanoplatelets. CrystEngComm, 2018, 20: 7473-7478

78 Leng M, Chen Z, Yang Y, et al. Lead-free, blue emitting bismuth halide perovskite quantum dots. Angew Chem Int Ed, 2016, 55: 15012-15016

79 Leng M, Yang Y, Chen Z, et al. Surface passivation of bismuthbased perovskite variant quantum dots to achieve efficient blue emission. Nano Lett, 2018, 18: 6076-6083

80 Shen Y, Yin J, Cai B, et al. Lead-free, stable, high-efficiency (52\%) blue luminescent $\mathrm{FA}_{3} \mathrm{Bi}_{2} \mathrm{Br}_{9}$ perovskite quantum dots. Nanoscale Horiz, 2020, 5: 580-585

81 Saparov B, Hong F, Sun JP, et al. Thin-film preparation and characterization of $\mathrm{Cs}_{3} \mathrm{Sb}_{2} \mathrm{I}_{9}$ : A lead-free layered perovskite semiconductor. Chem Mater, 2015, 27: 5622-5632

82 Giesbrecht N, Weis A, Bein T. Formation of stable 2D methylammonium antimony iodide phase for lead-free perovskite-like solar cells. J Phys Energy, 2020, 2: 024007

83 Jiang F, Yang D, Jiang Y, et al. Chlorine-incorporation-induced formation of the layered phase for antimony-based lead-free perovskite solar cells. J Am Chem Soc, 2018, 140: 1019-1027

84 Peng Y, Li F, Wang Y, et al. Enhanced photoconversion efficiency in cesium-antimony-halide perovskite derivatives by tuning crystallographic dimensionality. Appl Mater Today, 2020, 19: 100637

85 Harikesh PC, Mulmudi HK, Ghosh B, et al. Rb as an alternative cation for templating inorganic lead-free perovskites for solution processed photovoltaics. Chem Mater, 2016, 28: 7496-7504

86 Pal J, Manna S, Mondal A, et al. Colloidal synthesis and photophysics of $\mathrm{M}_{3} \mathrm{Sb}_{2} \mathrm{I}_{9}(\mathrm{M}=\mathrm{Cs}$ and $\mathrm{Rb}$ ) nanocrystals: Lead-free perovskites. Angew Chem Int Ed, 2017, 56: 14187-14191

87 Zhang J, Yang Y, Deng H, et al. High quantum yield blue emission from lead-free inorganic antimony halide perovskite colloidal quantum dots. ACS Nano, 2017, 11: 9294-9302

88 Johnston A, Dinic F, Todorović P, et al. Narrow emission from $\mathrm{Rb}_{3} \mathrm{Sb}_{2} \mathrm{I}_{9}$ nanoparticles. Adv Opt Mater, 2020, 8: 1901606

89 Takahashi $\mathrm{Y}$, Hasegawa H, Takahashi Y, et al. Hall mobility in tin iodide perovskite $\mathrm{CH}_{3} \mathrm{NH}_{3} \mathrm{SnI}_{3}$ : Evidence for a doped semiconductor. J Solid State Chem, 2013, 205: 39-43

90 Takahashi $\mathrm{Y}$, Obara R, Lin ZZ, et al. Charge-transport in tiniodide perovskite $\mathrm{CH}_{3} \mathrm{NH}_{3} \mathrm{SnI}_{3}$ : Origin of high conductivity. Dalton Trans, 2011, 40: 5563-5568

91 Kumar MH, Dharani S, Leong WL, et al. Lead-free halide perovskite solar cells with high photocurrents realized through vacancy modulation. Adv Mater, 2014, 26: 7122-7127

92 Mitzi DB, Feild CA, Harrison WTA, et al. Conducting tin halides with a layered organic-based perovskite structure. Nature, 1994, 369: 467-469

93 Lanzetta L, Marin-Beloqui JM, Sanchez-Molina I, et al. Twodimensional organic tin halide perovskites with tunable visible emission and their use in light-emitting devices. ACS Energy Lett, 2017, 2: 1662-1668

94 Zhang X, Wang C, Zhang Y, et al. Bright orange electroluminescence from lead-free two-dimensional perovskites. ACS Energy Lett, 2018, 4: 242-248 
95 Zhang R, Mao X, Cheng P, et al. Bismuth doped lead-free twodimensional tin based halide perovskite single crystals. J Energy Chem, 2019, 36: 1-6

96 Zimmermann I, Aghazada S, Nazeeruddin MK. Lead and HTM free stable two-dimensional tin perovskites with suitable band gap for solar cell applications. Angew Chem Int Ed, 2019, 58: 10721076

97 Wang Z, Wang F, Zhao B, et al. Efficient two-dimensional tin halide perovskite light-emitting diodes via a spacer cation substitution strategy. J Phys Chem Lett, 2020, 11: 1120-1127

98 Park I, Chu L, Leng K, et al. Highly stable two-dimensional tin(II) iodide hybrid organic-inorganic perovskite based on stilbene derivative. Adv Funct Mater, 2019, 29: 1904810

99 Park BW, Philippe B, Zhang X, et al. Bismuth based hybrid perovskites $\mathrm{A}_{3} \mathrm{Bi}_{2} \mathrm{I}_{9}$ (A: methylammonium or cesium) for solar cell application. Adv Mater, 2015, 27: 6806-6813

100 Pazoki M, Johansson MB, Zhu H, et al. Bismuth iodide perovskite materials for solar cell applications: Electronic structure, optical transitions, and directional charge transport. J Phys Chem C, 2016, 120: 29039-29046

101 Zhang Y, Liu Y, Xu Z, et al. Nucleation-controlled growth of superior lead-free perovskite $\mathrm{Cs}_{3} \mathrm{Bi}_{2} \mathrm{I}_{9}$ single-crystals for high-performance X-ray detection. Nat Commun, 2020, 11: 2304

102 Pious JK, Muthu C, Dani S, et al. Bismuth-based zero-dimensional perovskite-like materials: Effect of benzylammonium on dielectric confinement and photoconductivity. Chem Mater, 2020, 32: 2647-2652

103 Hebig JC, Kühn I, Flohre J, et al. Optoelectronic properties of $\left(\mathrm{CH}_{3} \mathrm{NH}_{3}\right)_{3} \mathrm{Sb}_{2} \mathrm{I}_{9}$ thin films for photovoltaic applications. ACS Energy Lett, 2016, 1: 309-314

104 Boopathi KM, Karuppuswamy P, Singh A, et al. Solution-processable antimony-based light-absorbing materials beyond lead halide perovskites. J Mater Chem A, 2017, 5: 20843-20850

105 Karuppuswamy P, Boopathi KM, Mohapatra A, et al. Role of a hydrophobic scaffold in controlling the crystallization of methylammonium antimony iodide for efficient lead-free perovskite solar cells. Nano Energy, 2018, 45: 330-336

106 Sun Z, Zeb A, Liu S, et al. Exploring a lead-free semiconducting hybrid ferroelectric with a zero-dimensional perovskite-like structure. Angew Chem, 2016, 128: 12033-12037

107 Zhou J, Luo J, Rong X, et al. Lead-free perovskite derivative $\mathrm{Cs}_{2} \mathrm{SnCl}_{6-x} \mathrm{Br}_{x}$ single crystals for narrowband photodetectors. Adv Opt Mater, 2019, 7: 1900139

108 Maughan AE, Ganose AM, Candia AM, et al. Anharmonicity and octahedral tilting in hybrid vacancy-ordered double perovskites. Chem Mater, 2018, 30: 472-483

109 Funabiki F, Toda Y, Hosono H. Optical and electrical properties of perovskite variant $\left(\mathrm{CH}_{3} \mathrm{NH}_{3}\right)_{2} \mathrm{SnI}_{6}$. J Phys Chem C, 2018, 122: 10749-10754

110 Maughan AE, Ganose AM, Almaker MA, et al. Tolerance factor and cooperative tilting effects in vacancy-ordered double perovskite halides. Chem Mater, 2018, 30: 3909-3919

111 Maughan AE, Ganose AM, Bordelon MM, et al. Defect tolerance to intolerance in the vacancy-ordered double perovskite semiconductors $\mathrm{Cs}_{2} \mathrm{SnI}_{6}$ and $\mathrm{Cs}_{2} \mathrm{TeI}_{6}$. J Am Chem Soc, 2016, 138: 84538464

112 Zhang X, Cao W, Wang W, et al. Efficient light-emitting diodes based on green perovskite nanocrystals with mixed-metal cations. Nano Energy, 2016, 30: 511-516

113 Li J, Tan Z, Hu M, et al. Antimony doped $\mathrm{Cs}_{2} \mathrm{SnCl}_{6}$ with bright and stable emission. Front Optoelectron, 2019, 12: 352-364

114 Tan Z, Li J, Zhang C, et al. Highly efficient blue-emitting Bidoped $\mathrm{Cs}_{2} \mathrm{SnCl}_{6}$ perovskite variant: Photoluminescence induced by impurity doping. Adv Funct Mater, 2018, 28: 1801131

115 Gonzalez-Carrero S, Espallargas GM, Galian RE, et al. Blue-luminescent organic lead bromide perovskites: Highly dispersible and photostable materials. J Mater Chem A, 2015, 3: 14039-14045

116 Zuo F, Williams ST, Liang PW, et al. Binary-metal perovskites toward high-performance planar-heterojunction hybrid solar cells. Adv Mater, 2014, 26: 6454-6460

117 Hao F, Stoumpos CC, Cao DH, et al. Lead-free solid-state organic-inorganic halide perovskite solar cells. Nat Photon, 2014, 8: 489-494

118 Koh TM, Krishnamoorthy T, Yantara N, et al. Formamidinium tin-based perovskite with low $E_{\mathrm{g}}$ for photovoltaic applications. J Mater Chem A, 2015, 3: 14996-15000

119 Ogomi Y, Morita A, Tsukamoto S, et al. $\mathrm{CH}_{3} \mathrm{NH}_{3} \mathrm{Sn}_{x} \mathrm{~Pb}_{(1-x)} \mathrm{I}_{3}$ perovskite solar cells covering up to $1060 \mathrm{~nm}$. J Phys Chem Lett, 2014, 5: 1004-1011

120 Hao F, Stoumpos CC, Chang RPH, et al. Anomalous band gap behavior in mixed $\mathrm{Sn}$ and $\mathrm{Pb}$ perovskites enables broadening of absorption spectrum in solar cells. J Am Chem Soc, 2014, 136: 8094-8099

121 Berdiyorov GR, Madjet ME, El-Mellouhi F. Improved electronic transport properties of tin-halide perovskites. Sol Energy Mater Sol Cells, 2017, 170: 8-12

122 Lee S, Ha TJ, Kang DW. Mixed-halide Pb-Sn binary perovskite films with various $\mathrm{Sn}$-content for $\mathrm{Pb}$-reduced solar cells. Mater Lett, 2018, 227: 311-314

123 Wang Y, Fu W, Yan J, et al. Low-bandgap mixed tin-lead iodide perovskite with large grains for high performance solar cells. J Mater Chem A, 2018, 6: 13090-13095

124 Hao F, Stoumpos CC, Guo P, et al. Solvent-mediated crystallization of $\mathrm{CH}_{3} \mathrm{NH}_{3} \mathrm{SnI}_{3}$ films for heterojunction depleted perovskite solar cells. J Am Chem Soc, 2015, 137: 11445-11452

125 Weiss M, Horn J, Richter C, et al. Preparation and characterization of methylammonium tin iodide layers as photovoltaic absorbers. Phys Status Solidi A, 2016, 213: 975-981

126 Yang Z, Wang Y, Liu Y. Stability and charge separation of different $\mathrm{CH}_{3} \mathrm{NH}_{3} \mathrm{SnI}_{3} / \mathrm{TiO}_{2}$ interface: A first-principles study. Appl Surf Sci, 2018, 441: 394-400

127 Gao F, Li C, Qin L, et al. Enhanced performance of tin halide perovskite solar cell by addition of lead thiocyanate. RSC Adv, 2018, 8: 14025-14030

$128 \mathrm{Ke}$ W, Stoumpos CC, Zhu M, et al. Enhanced photovoltaic performance and stability with a new type of hollow 3D perovskite

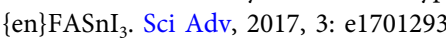

129 Zhao Z, Gu F, Li Y, et al. Mixed-organic-cation tin iodide for lead-free perovskite solar cells with an efficiency of $8.12 \%$. Adv Sci, 2017, 4: 1700204

130 Jokar E, Chien CH, Fathi A, et al. Slow surface passivation and crystal relaxation with additives to improve device performance and durability for tin-based perovskite solar cells. Energy Environ Sci, 2018, 11: 2353-2362

131 Ran C, Xi J, Gao W, et al. Bilateral interface engineering toward efficient 2D-3D bulk heterojunction tin halide lead-free perovskite solar cells. ACS Energy Lett, 2018, 3: 713-721

132 Liu X, Wu T, Chen JY, et al. Templated growth of $\mathrm{FASnI}_{3}$ crystals for efficient tin perovskite solar cells. Energy Environ Sci, 2020, 13: 2896-2902 
133 Sabba D, Mulmudi HK, Prabhakar RR, et al. Impact of anionic $\mathrm{Br}^{-}$substitution on open circuit voltage in lead free perovskite $\left(\mathrm{CsSnI}_{3-x} \mathrm{Br}_{x}\right)$ solar cells. J Phys Chem C, 2015, 119: 1763-1767

134 Gupta S, Bendikov T, Hodes G, et al. $\mathrm{CsSnBr}_{3}$, a lead-free halide perovskite for long-term solar cell application: Insights on $\mathrm{SnF}_{2}$ addition. ACS Energy Lett, 2016, 1: 1028-1033

135 Lee B, Krenselewski A, Baik SI, et al. Solution processing of airstable molecular semiconducting iodosalts, $\mathrm{Cs}_{2} \mathrm{SnI}_{6-x} \mathrm{Br}_{x}$, for potential solar cell applications. Sustain Energy Fuels, 2017, 1: 710724

136 Zhu W, Xin G, Wang Y, et al. Tunable optical properties and stability of lead free all inorganic perovskites $\left(\mathrm{Cs}_{2} \mathrm{SnI}_{x} \mathrm{Cl}_{6-x}\right)$. J Mater Chem A, 2018, 6: 2577-2584

137 Qiu X, Cao B, Yuan S, et al. From unstable $\mathrm{CsSnI}_{3}$ to air-stable $\mathrm{Cs}_{2} \mathrm{SnI}_{6}$ : A lead-free perovskite solar cell light absorber with bandgap of $1.48 \mathrm{eV}$ and high absorption coefficient. Sol Energy Mater Sol Cells, 2017, 159: 227-234

138 Qiu X, Jiang Y, Zhang $\mathrm{H}$, et al. Lead-free mesoscopic $\mathrm{Cs}_{2} \mathrm{SnI}_{6}$ perovskite solar cells using different nanostructured $\mathrm{ZnO}$ nanorods as electron transport layers. Phys Status Solidi RRL, 2016, 10: 587591

139 Ke JCR, Lewis DJ, Walton AS, et al. Ambient-air-stable inorganic $\mathrm{Cs}_{2} \mathrm{SnI}_{6}$ double perovskite thin films via aerosol-assisted chemical vapour deposition. J Mater Chem A, 2018, 6: 11205-11214

140 Wu C, Zhang Q, Liu Y, et al. The dawn of lead-free perovskite solar cell: Highly stable double perovskite $\mathrm{Cs}_{2} \mathrm{AgBiBr}_{6}$ film. Adv Sci, 2018, 5: 1700759

141 Ning W, Wang F, Wu B, et al. Long electron-hole diffusion length in high-quality lead-free double perovskite films. Adv Mater, 2018, 30: 1706246

142 Gao W, Ran C, Xi J, et al. High-quality $\mathrm{Cs}_{2} \mathrm{AgBiBr}_{6}$ double perovskite film for lead-free inverted planar heterojunction solar cells with $2.2 \%$ efficiency. ChemPhysChem, 2018, 19: 1696-1700

143 Igbari $\mathrm{F}$, Wang R, Wang ZK, et al. Composition stoichiometry of $\mathrm{Cs}_{2} \mathrm{AgBiBr}_{6}$ films for highly efficient lead-free perovskite solar cells. Nano Lett, 2019, 19: 2066-2073

144 Fan P, Peng HX, Zheng ZH, et al. Single-source vapor-deposited $\mathrm{Cs}_{2} \mathrm{AgBiBr}_{6}$ thin films for lead-free perovskite solar cells. Nanomaterials, 2019, 9: 1760

145 Zhang $\mathrm{Z}, \mathrm{Wu} \mathrm{C}$, Wang $\mathrm{D}$, et al. Improvement of $\mathrm{Cs}_{2} \mathrm{AgBiBr}_{6}$ double perovskite solar cell by rubidium doping. Org Electron, 2019, 74: 204-210

146 Pantaler M, Cho KT, Queloz VIE, et al. Hysteresis-free lead-free double-perovskite solar cells by interface engineering. ACS Energy Lett, 2018, 3: 1781-1786

147 Longo G, Mahesh S, Buizza LRV, et al. Understanding the performance-limiting factors of $\mathrm{Cs}_{2} \mathrm{AgBiBr}_{6}$ double-perovskite solar cells. ACS Energy Lett, 2020, 5: 2200-2207

148 Shin SS, Correa Baena JP, Kurchin RC, et al. Solvent-engineering method to deposit compact bismuth-based thin films: Mechanism and application to photovoltaics. Chem Mater, 2018, 30: 336-343

149 Jain SM, Phuyal D, Davies ML, et al. An effective approach of vapour assisted morphological tailoring for reducing metal defect sites in lead-free, $\left(\mathrm{CH}_{3} \mathrm{NH}_{3}\right)_{3} \mathrm{Bi}_{2} \mathrm{I}_{9}$ bismuth-based perovskite solar cells for improved performance and long-term stability. Nano Energy, 2018, 49: 614-624

150 Quan LN, García de Arquer FP, Sabatini RP, et al. Perovskites for light emission. Adv Mater, 2018, 30: 1801996

151 Liu $\mathrm{H}$, Wu Z, Shao J, et al. $\mathrm{CsPb}_{x} \mathrm{Mn}_{1-x} \mathrm{Cl}_{3}$ perovskite quantum dots with high Mn substitution ratio. ACS Nano, 2017, 11: 2239-
2247

152 Zhou $\mathrm{C}$, Lin $\mathrm{H}$, Tian $\mathrm{Y}$, et al. Luminescent zero-dimensional organic metal halide hybrids with near-unity quantum efficiency. Chem Sci, 2018, 9: 586-593

153 Lai ML, Tay TYS, Sadhanala A, et al. Tunable near-infrared luminescence in tin halide perovskite devices. J Phys Chem Lett, 2016, 7: 2653-2658

154 Yuan F, Zheng X, Johnston A, et al. Color-pure red light-emitting diodes based on two-dimensional lead-free perovskites. Sci Adv, 2020, 6: eabb0253

155 Zhang H, Gao Z, Liang R, et al. X-ray detector based on allinorganic lead-free $\mathrm{Cs}_{2} \mathrm{AgBiBr}_{6}$ perovskite single crystal. IEEE Trans Electron Devices, 2019, 66: 2224-2229

156 Yuan Y, Huang J. Ion migration in organometal trihalide perovskite and its impact on photovoltaic efficiency and stability. Acc Chem Res, 2016, 49: 286-293

157 Lin Y, Bai Y, Fang Y, et al. Suppressed ion migration in lowdimensional perovskites. ACS Energy Lett, 2017, 2: 1571-1572

158 Haruyama J, Sodeyama K, Han L, et al. First-principles study of ion diffusion in perovskite solar cell sensitizers. J Am Chem Soc, 2015, 137: 10048-10051

159 Wei W, Zhang Y, Xu Q, et al. Monolithic integration of hybrid perovskite single crystals with heterogenous substrate for highly sensitive X-ray imaging. Nat Photon, 2017, 11: 315-321

160 Yin $\mathrm{L}, \mathrm{Wu} \mathrm{H}, \mathrm{Pan} \mathrm{W}$, et al. Controlled cooling for synthesis of $\mathrm{Cs}_{2} \mathrm{AgBiBr}_{6}$ single crystals and its application for X-ray detection. Adv Opt Mater, 2019, 7: 1900491

$161 \mathrm{Xu} \mathrm{Z}$, Liu X, Li Y, et al. Exploring lead-free hybrid double perovskite crystals of $(\mathrm{BA})_{2} \mathrm{CsAgBiBr}_{7}$ with large mobility-lifetime product toward X-ray detection. Angew Chem Int Ed, 2019, 58: $15757-15761$

162 Liu Y, Zhang Y, Yang Z, et al. Large lead-free perovskite single crystal for high-performance coplanar X-ray imaging applications. Adv Opt Mater, 2020, 8: 2000814

163 Tie S, Zhao W, Xin D, et al. Robust fabrication of hybrid lead-free perovskite pellets for stable X-ray detectors with low detection limit. Adv Mater, 2020, 32: 2001981

Acknowledgements The authors thank the Ministry of Science and Technology (2017YFA0205004, 2016YFA0200700), the Strategic Priority Research Program of the Chinese Academy of Sciences (XDB36000000), the National Natural Science Foundation of China (61704038, 21673054, 11874130, 12074086, 61307120, 61704038 and 11474187), the Open Research Fund Program of the State Key Laboratory of Low-Dimensional Quantum Physics (KF201902), and the CAS Instrument Development Project (Y950291) for their support.

Author contributions Yang F wrote the draft; Wang A, Yue S, Du W, Wang $\mathrm{S}$ and Zhang $\mathrm{X}$ revised the manuscript; Liu X led the project.

Conflict of interest The authors declare that they have no conflict of interest. 


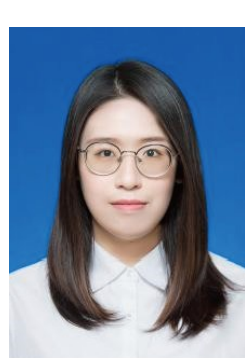

Fan Yang received her bachelor's degree (2018) from Liaoning University. She is now pursuing a master's degree at Tianjin University. Since June 2019 she has been a joint student at the National Center for Nanoscience and Technology (NCNST) under the supervision of Prof. Xinfeng Liu. Her research interests focus on the growth and optical properties of single-crystal perovskites.

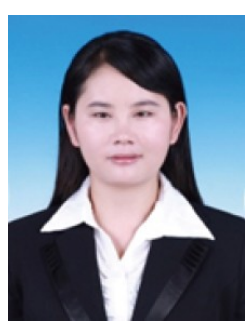

Shaoli Wang received her PhD degree from the Institute of Chemistry, Chinese Academic Sciences in 2014. Then she joined the Experiment Center of Forestry in North China of the Chinese Academy of Forestry and engaged in materialrelated scientific research. At the end of August 2019, she joined the research group of Xinfeng Liu at the NCNST. Her research interests focus on new nano materials.

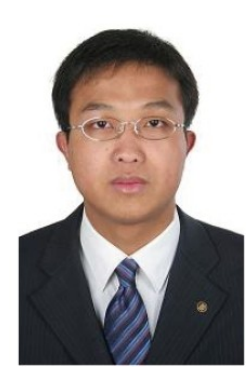

Xiaotao Zhang is an associate research fellow of Tianjin University. He received his $\mathrm{PhD}$ degree from the Institute of Chemistry, Chinese Academy of Sciences in 2012. Then he worked at the same institute as a postdoctoral fellow. Since 2015, he has been working as an associate research fellow at Tianjin University. His research group mainly focuses on the preparation of organic cocrystals and devices, organic optoelectronic materials, and the printing of thin film and flexible devices.

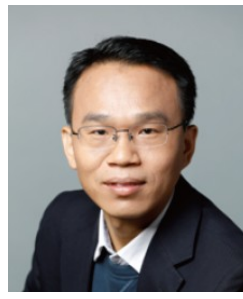

Xinfeng Liu is a professor at the NCNST in China. He received his $\mathrm{PhD}$ in 2011 at the NCNST. Then he joined the School of Physical and Mathematical Sciences of Nanyang Technological University, Singapore, as a postdoctoral fellow. He joined the "100-Talents" Program of the Chinese Academy of Sciences in 2015 and then became a professor at the NCNST. His research group mainly focuses on light-matter interactions and ultrafast spectroscopy at the micro-/nano-scale.

\section{非铅钙钛矿的合成、性质和应用}

杨凡 ${ }^{1,2}$, 王傲成 ${ }^{1,2}$, 岳帅 ${ }^{2,3}$, 杜文娜 ${ }^{2,3}$, 王少丽 ${ }^{2,4^{*}}$, 张小涛 ${ }^{1^{*}}$, 刘新风 ${ }^{2,3 *}$

摘要 卤化铅钻钛矿由于具有高吸收系数、高载流子迁移率、高 缺陷容忍度和高光致发光效率等优异的光电子性能, 近年来引起 了人们的广泛关注. 然而, 阻碍其广泛应用的一个关键问题是铅元 素引起的毒性. 为了解决这一问题, 使用其他无毒元素替代铅是一 个很有前途的研究方向. 在综合考虑原子半径、相对原子质量、 电子排布等条件下, 以锡、铋、锑等元素代替铅的类钙钛矿已被 广泛合成. 本文从制备方法、光电性质、器件应用等几个方面综 述了这几类非铅基钲铁矿. 首先, 介绍了非铅基钲钛矿主要的制备 方法: 溶液法、固相反应法和化学气相沉积法; 其次, 从不同结构维 度讨论了非铅基钻钛矿的光电性能及其性能优化方法; 最后, 讨论 了非铅基钻钛矿在太阳能电池、发光二极管和 X射线探测器中的 应用. 希望本综述能给未来非铅钻钛矿的研究和发展提供一定的 参考价值. 